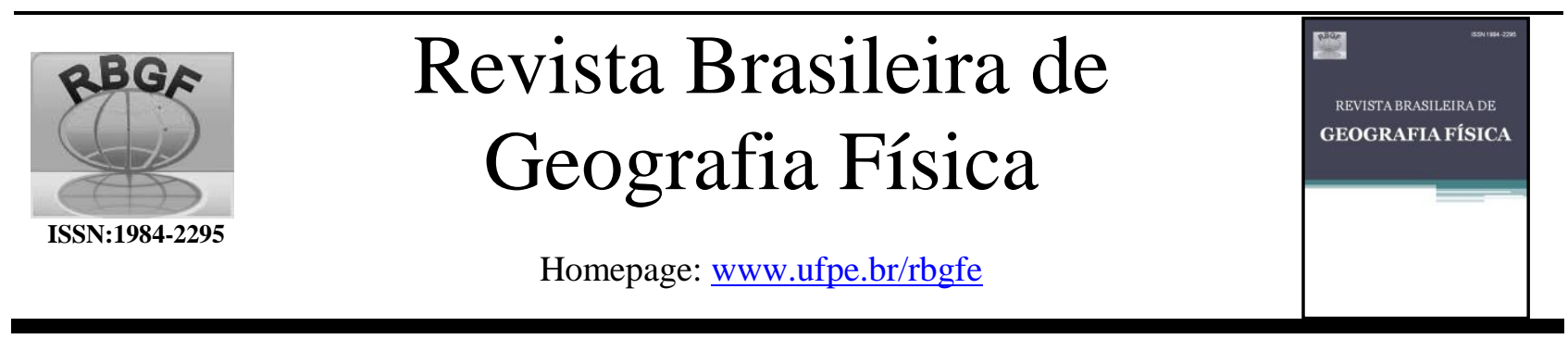

\title{
Metodologia para diagnóstico de cursos de água inseridos em áreas urbanas ${ }^{1}$
}

\author{
Greyce Bernardes de Mello Rezende \\ UFMT. Autor correspondente: e-mail: greycebernardes@yahoo.com.br \\ Sergio Murilo Santos de Araújo \\ UFCG. e-mail: sergiomurilosa.ufcg@gmail.com
}

Artigo recebido em 13/11/2017 e aceito em 30/05/2018

\begin{abstract}
R E S U M O
Em vista da carência de metodologias que incluam os aspectos ambientais e urbanos voltados no diagnóstico da relação rio-cidade, este trabalho apresenta uma proposta de metodologia com tal finalidade, buscando integrar variáveis ambientais, urbanas e fluviais. Para tanto, têm-se como objetivo propor um modelo metodológico de diagnóstico de cursos de água urbanos através de uma perspectiva urbano-ambiental e de abordagem das vulnerabilidades socioambientais. Dessa forma a metodologia abarca três etapas, a saber: a) mapeamento dos níveis de vulnerabilidade socioambiental; b) mapeamento do grau de impermeabilização e tempo de concentração das sub-bacias; c) diagnóstico das margens dos rios, através dos aspectos ambientais, fluviais e de uso e ocupação. A fim de exemplificar a utilização da metodologia, foi efetuada sua aplicação em trecho do rio Araguaia e das Garças, na área urbana de três cidades: Barra do Garças - MT, Pontal do Araguaia - MT e Aragarças - GO, no Brasil. Ao final, observa-se que a metodologia proposta foi capaz de apontar um resultado eficaz, indicando trechos de degradação ambiental dos corpos hídricos bem como as áreas de vulnerabilidade socioambiental decorrentes de riscos de inundações, o que demonstra a importância de uma interface entre os aspectos urbanos e ambientais no trato das margens dos rios urbanos bem como de suas sub-bacias. Palavras-chave: rio-cidade, rios urbanos, indicadores, diagnóstico
\end{abstract}

\section{Methodology to diagnosis of water courses inserted in urban areas}

\begin{abstract}
A B S T R A C T
In view of the lack of methodologies that include the environmental and urban aspects focused on the diagnosis of the river-city relationship, this paper presents a methodology for this purpose, seeking to integrate environmental, urban and river variables. Therefore, the objective is to propose a methodological model for the diagnosis of urban watercourses through an urban-environmental perspective and to approach socio-environmental vulnerabilities. In this way the methodology has three stages: a) mapping of the socio-environmental vulnerability levels; b) Mapping of the degree of waterproofing and time of concentration of sub-basins; c) Diagnosis of river banks, through environmental, river and use and occupancy aspects. In order to exemplify the use of the methodology, it was applied in the Araguaia and Garças rivers, in the urban area of three cities: Barra do Garças - MT, Pontal do Araguaia - MT and Aragarças - GO, in Brazil. At the end, it can be observed that the proposed methodology was able to indicate an effective result, indicating the environmental degradation of the water bodies as well as the socio-environmental vulnerability areas due to flood risks, which demonstrates the importance of an interface between the aspects Urban and environmental conditions in the treatment of urban river banks as well as their sub-basins.
\end{abstract}

Keyword: River-city, urban rivers, indicators, diagnosis

\section{Introdução}

\footnotetext{
1 Pesquisa extraída da tese: “AS CIDADES E AS ÁGUAS: uma abordagem metodológica das vulnerabilidades socioambientais dos rios Araguaia e das Garças, nos municípios de Barra do Garças, Pontal do Araguaia e Aragarças”, à qual recebeu menção honrosa em Ciências Ambientais no Prêmio Capes de Teses de 2016.
}

É certo que a relação rio-cidade é marcada por algumas problemáticas, dentre elas citam-se 
ocupações ilegais de áreas de preservação permanente, em especial às margens de rios, as quais submetem os ocupantes a riscos frequentes de inundações, bem como o processo de urbanização dessas margens e até mesmo da bacia hidrográfica, o que pode potencializar inundações mais intensas.

Assim, deve-se caminhar para uma discussão de como estabelecer uma relação conciliatória entre a questão ambiental e urbana, que, habitualmente, são analisadas isoladamente. Nesse contexto, a construção de um modelo viável de gestão ambiental urbana, resguardando a proteção dos recursos ambientais e a qualidade de vida, implica na abordagem integrada dos aspectos ambientais, relativos aos componentes do meio físico (abióticos) e do meio biótico, além dos aspectos urbanísticos, relativos às especificidades socioculturais do meio urbano.

Ter uma visão integralizada é de fundamental importância quando se intervém em um contexto tão antrópico, pois um rio revitalizado, com as margens preservadas e solo permeável, é essencial para o equilíbrio ambiental e a qualidade de vida dos cidadãos. Para tanto, é necessário considerar essas áreas como um espaço híbrido e com múltiplas funções: ambiental, urbanísticas e paisagísticas (Mello, 2008).

Destarte, o diagnóstico de corpos d'água em áreas urbanas deve considerar as condições físicas e ambientais do curso fluvial, mas principalmente informações relevantes do entorno, como aspectos econômicos, urbanos e sociais. Para tanto, devem ser empregadas metodologias que auxiliem na coleta de dados confiáveis, mediante uma avaliação sólida das condições de degradação dos corpos hídricos, bem como suas características peculiares.

Diante do exposto, ressalta-se que o objetivo do presente artigo é propor um modelo metodológico de diagnóstico de cursos de água urbanos através de uma perspectiva urbanoambiental e de abordagem das vulnerabilidades socioambientais, visando dar suporte ao planejamento das margens dos rios urbanos, através de uma análise da situação atual da dinâmica fluvial, das suas margens e da bacia/subbacia as quais estão inseridas com suas vulnerabilidades.

Esse modelo abarca diferentes escalas presentes na relação rio $\mathrm{x}$ cidade, a saber: a) a escala da cidade, com o mapeamento dos níveis de vulnerabilidade socioambiental presentes; b) a escala das sub-bacias, com variáveis que trabalham a influência do grau de impermeabilização e escoamento superficial; c) a escala das margens dos rios, através dos diversos aspectos ambientais, fluviais e de uso e ocupação das mesmas.

Por fim, salienta-se que para demonstrar sua viabilidade, a metodologia foi aplicada em trecho do rio Araguaia e das Garças, na área urbana de três cidades, conforme exposto a seguir.

\section{Metodologia}

A metodologia que se apresenta nesse artigo estrutura-se em três etapas, as quais são detalhadas a seguir. Posteriormente, é realizada sua aplicação em um estudo de caso, de forma a facilitar sua compreensão.

O caso em comento, trata-se de diagnóstico de trecho do rio Araguaia e das Garças na área urbana de três cidades: Barra do Garças- MT, Pontal do Araguaia - MT e Aragarças- GO, no Brasil.

Salienta-se que o rio Araguaia pertencente à Bacia Araguaia - Tocantins, drena uma área de 365 mil km² e é dividido em três etapas, sendo: Alto Araguaia, das nascentes até Barra do Garças, Médio Araguaia, e Baixo Araguaia; e o trecho de estudo se localiza na parte final do Alto Araguaia. Já o rio das Garças tem suas principais nascentes no município de Alto Garças e desagua no rio Araguaia, exatamente no trecho da área de estudo, conforme pode ser observado na Figura 1. 


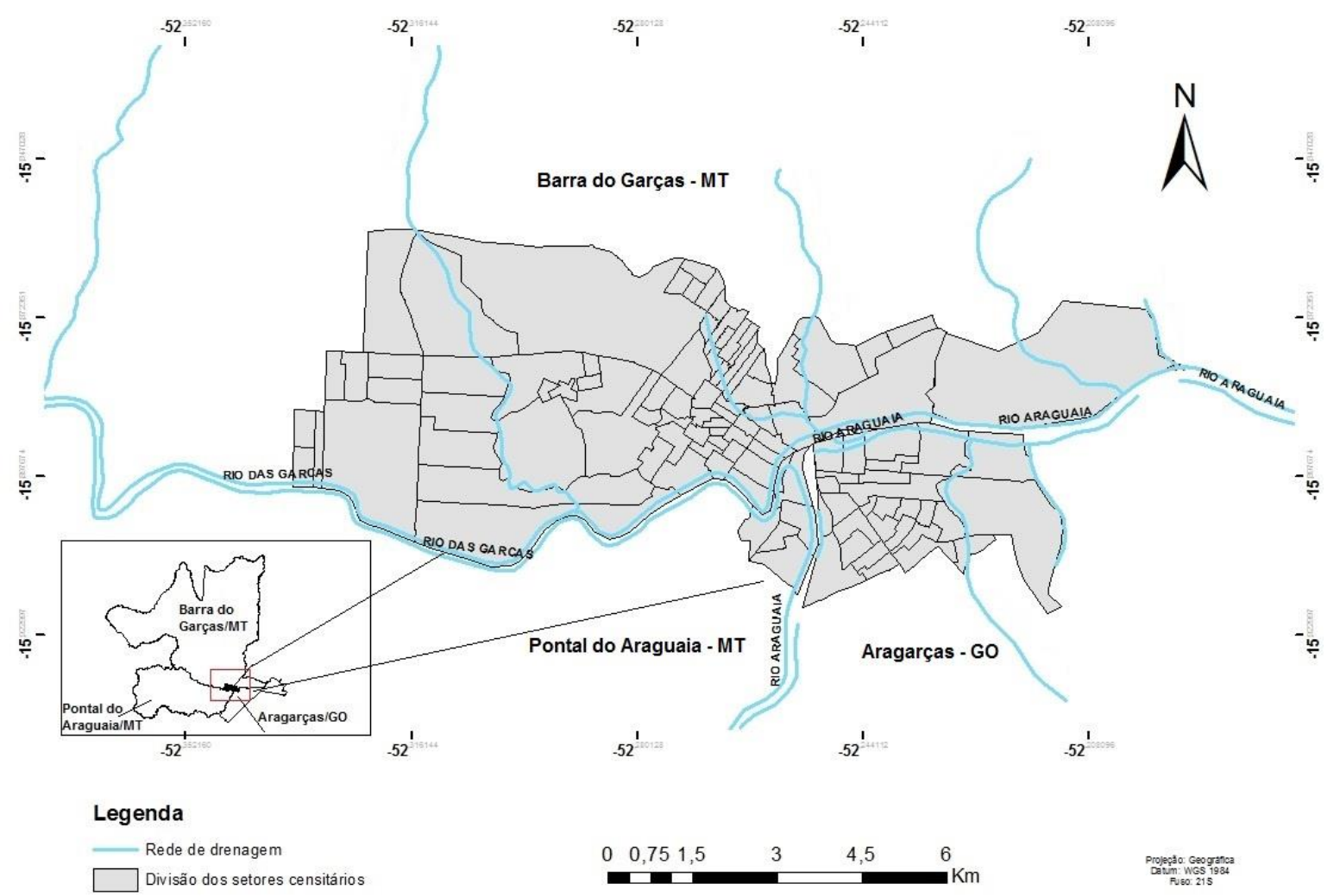

Figura 1. Rio das Garças e Araguaia na área de estudo.

A Figura 2 apresenta um esquema das variáveis utilizadas na metodologia.

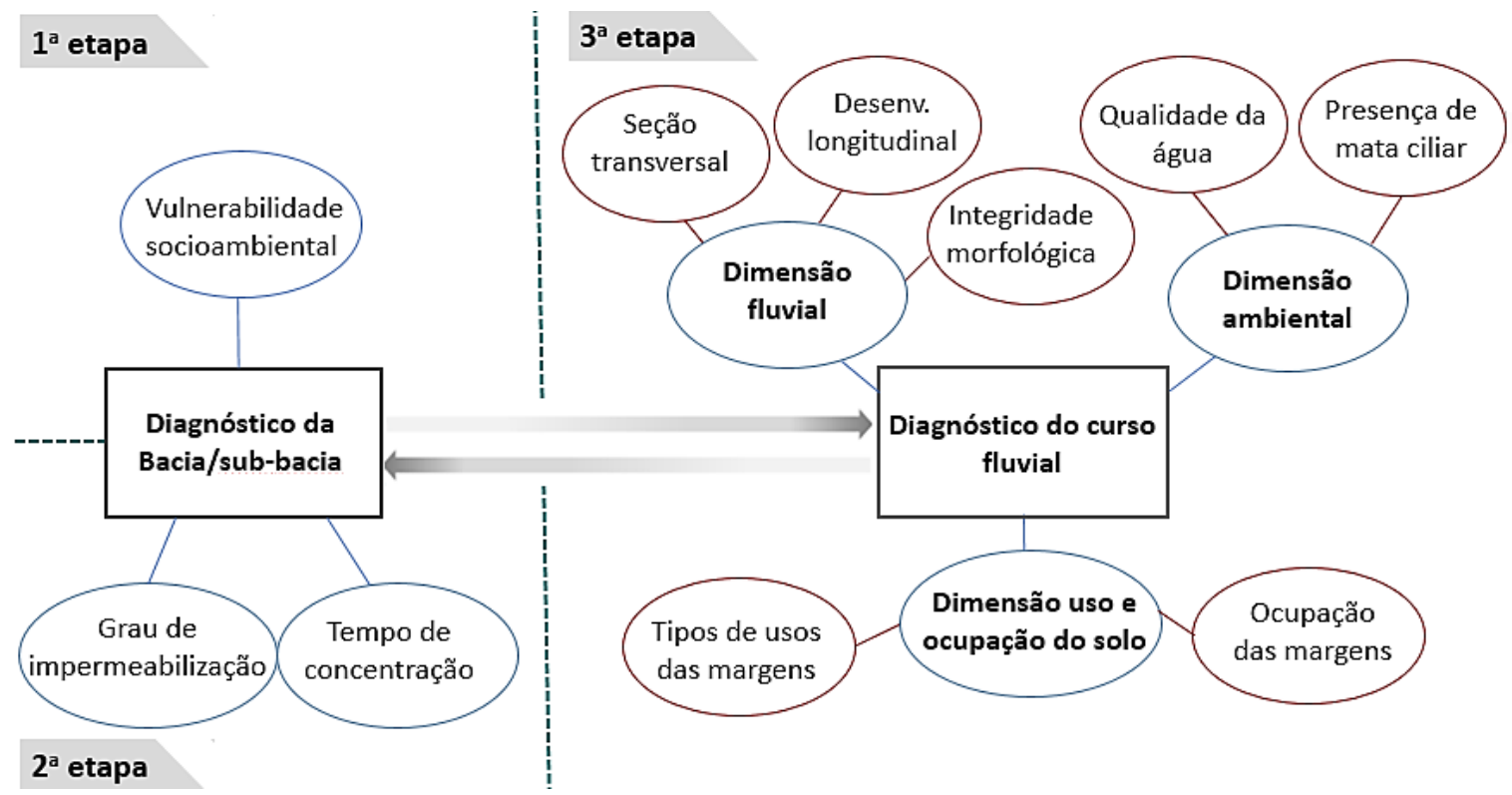

Figura 2. Representação das dimensões e variáveis analisadas

O diagnóstico da bacia/sub-bacia divide-se nas duas primeiras etapas da metodologia: A primeira concentra-se no mapeamento da vulnerabilidade socioambiental, reconhecendo as áreas onde a população de vulneráveis se apresenta no contexto urbano da área de estudo. Para tanto, a análise de riscos de inundação das margens 
de rios e vulnerabilidade social foi feita a partir do Índice de Vulnerabilidade Socioambiental (IVSA). Ressalta-se que o levantamento de áreas de risco pode apontar a necessidade de remoção ou a previsão de meios de se evitar a sua ocupação.

A segunda etapa consiste em analisar aspectos relacionados à ocupação/ impermeabilização das sub-bacias e respectivos tempos de concentração, uma vez que tais fatores influenciam as condições fluviais e ambientais dos cursos d'água.

A terceira etapa refere-se ao diagnóstico do curso fluvial, de forma que o mesmo foi dividido em três dimensões: uso e ocupação do solo, fluvial e ambiental. As condições de uso e ocupação do solo das áreas marginais podem assumir papel decisivo sobre as condições de equilíbrio do curso d'água. Já as demais dimensões se baseiam na análise do nível de alteração em relação à condição natural de cada trecho do curso fluvial por meio de um conjunto de indicadores, que contemplam desde aspectos como alterações geomorfológicas, presença de mata ciliar e de qualidade da água, uma vez que essas condições são importantes para a verificação de degradação dos rios.

Através do diagnóstico das subbacias, diversas medidas podem ser adotadas: desde medidas mitigatórias em relação ao gerenciamento de risco, sugestões no tocante à legislação urbanística (como taxa de ocupação e permeabilidade do solo), até programas de educação ambiental.

Em relação ao curso d'água, foram definidos trechos de conservação, trechos com potenciais de restauração, e trechos altamente degradados. A partir de seu diagnóstico, propostas de conservação ou intervenção podem ser implementadas.

\section{$1^{a} \quad$ Etapa: Diagnóstico $d a$ Vulnerabilidade socioambiental}

Para avaliar as vulnerabilidades sociais da área de estudo e posterior elaboração de um índice, foram coletadas variáveis socioeconômicas do Censo 2010 do Instituto Brasileiro de Geografia e Estatística - IBGE. Para as cidades de Barra do Garças, Aragarças e Pontal do Araguaia, esses dados estão disponibilizados apenas por setor censitário, sendo, portanto, a menor unidade de análise. São 115 setores censitários inseridos na área urbana dos municípios. (78 de Barra do Garças, 6 de Pontal do Araguaia e 31 em Aragarças).

Foram utilizados 23 indicadores, os quais, para aplicação de forma mais didática, foram agrupados em subgrupos homogêneos, denominados de temas e, também em grupos denominados de dimensões. Em seguida, conforme Figura 3, estipulou-se 5 dimensões que pudessem contemplar os diversos aspectos da vulnerabilidade social, a saber: as condições dos chefes de família, as condições da família, a condição econômica, a situação dos domicílios, e por fim a infraestrutura urbana disponibilizadas para esses domicílios.

Ainda conforme Figura 3, esses indicadores possuem relação de negatividade ou positividade com a vulnerabilidade, isto é, contribuindo para seu aumento ou redução, e possuem fórmulas diferentes para seu cálculo, conforme detalhado no item a seguir. 


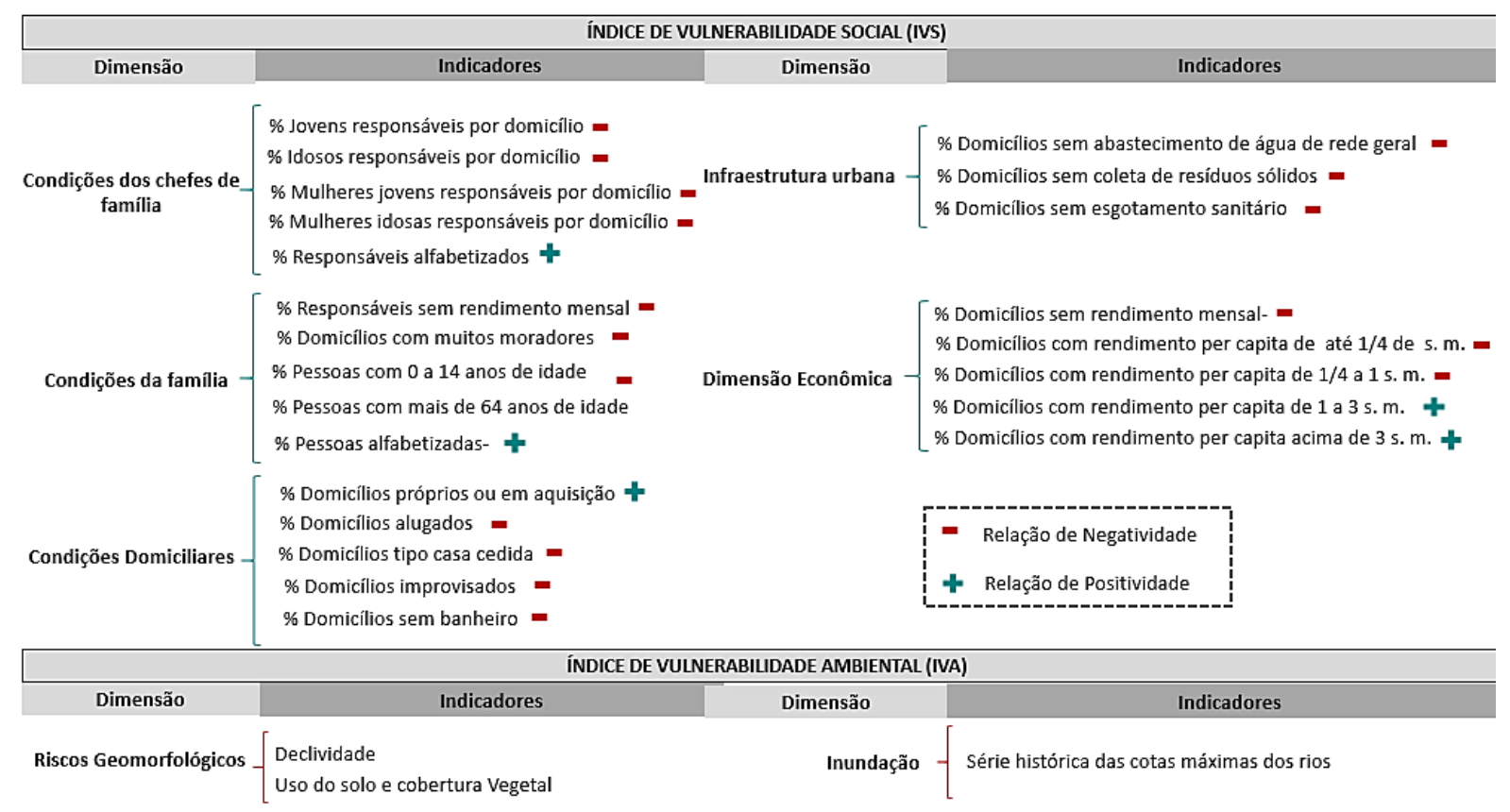

Figura 3. Representação dos indicadores e índices da Vulnerabilidade Socioambiental da área de estudo

Após identificar a relação positiva ou negativa da variável com o processo de vulnerabilidade socioeconômico, foi feita a operacionalização para o cálculo do índice a partir de fórmulas que reconhecem essas relações e permitem a análise da vulnerabilidade através da agregação de todos os índices. Tais fórmulas são demonstradas no Quadro 1.

Quadro 1. Fórmula dos índices conforme o tipo de relação (positiva ou negativa)

\begin{tabular}{|cl|}
\hline $\begin{array}{l}\text { Quando a relação é } \\
\text { positiva: }\end{array}$ & $\begin{array}{l}\text { Quando a relação } \\
\text { é negativa: }\end{array}$ \\
\hline $\mathrm{I}=\frac{(\mathrm{M}-\mathrm{x})}{(\mathrm{M}-\mathrm{m})}$ & $\mathrm{I}=\underline{(\mathrm{x}-\mathrm{m})}$ \\
\hline
\end{tabular}

Onde:

I = índice calculado para cada setor censitário da área de estudo

$\mathrm{x}=$ valor observado de cada variável em cada setor censitário

$\mathrm{m}=$ valor mínimo identificado em todos os setores censitários

$\mathrm{M}=$ valor máximo identificado em todos os setores censitários
Como se pode observar na fórmula apresentada, fez-se necessário escolher os níveis mínimos e máximos para cada indicador; em seguida, foi feita uma comparação dos valores observados em cada um dos setores censitários analisados, sempre com o menor e o maior dentre todos os demais setores da área de estudo analisada.

Efetuado o cálculo do índice para cada indicador, é realizada a agregação desses índices por dimensão através da média aritmética, chegando-se ao índice das cinco dimensões: Condições dos chefes de família, Condições da família, Condições domiciliares, Insfraestrutura Urbana e Dimensão econômica. Por último, o Índice de Vulnerabilidade Social (IVS) dos setores censitários foi calculado pela média aritmética dos índices das cinco dimensões.

No tocante à vulnerabilidade ambiental, ressalta-se que é importante diagnosticar áreas de riscos quanto à inundação. Para tanto, trabalhou-se com a série histórica de inundações, através da junção de dados como as cotas máximas do rio Araguaia e das curvas de níveis do local. Foram confeccionados mapas de manchas de inundação com os seguintes intervalos: 
a) Vulnerabilidade Ambiental quanto à Inundação MUITO ALTA - frequência de inundação anual e cota de até $550 \mathrm{~cm}$;

b) Vulnerabilidade Ambiental quanto à Inundação ALTA - frequência de inundação entre 1 a 2 anos de inundação e cota de 550 a $800 \mathrm{~cm}$;

c) Vulnerabilidade Ambiental quanto à Inundação MÉDIA - frequência de inundação entre 2 a 10 anos e cota de 800 a $1050 \mathrm{~cm}$;

d) Vulnerabilidade Ambiental quanto à Inundação BAIXA - frequência de inundação entre 10 a 24 anos e cota de 1050 a $1300 \mathrm{~cm}$;

e) Vulnerabilidade Ambiental quanto à Inundação MUITO BAIXA - frequência de inundação acima de 24 anos e cota acima de $1300 \mathrm{~cm}$.

Quadro 2 mostra a classificação e representação da variação das áreas mapeadas pela cor correspondente, conforme uma escala definida para este estudo:

Quadro 2. Classificação e Representação dos Índices em Níveis de Vulnerabilidade Ambiental quanto à inundação

\begin{tabular}{|l|l|l|}
\hline $\begin{array}{c}\text { NÍVEL DE VULNERABILIDADE } \\
\text { AMBIENTAL QUANTO } \mathbf{A} \\
\text { INUNDAÇÃO }\end{array}$ & $\begin{array}{c}\text { ÍNDICE } \\
\text { CORRESPONDENT } \\
\text { E }\end{array}$ & COLORAÇÃO \\
\hline Muito alto & 1,00 & \\
\hline Alto & 0,80 & \\
\hline Médio & 0,60 & \\
\hline Baixo & 0,40 & \\
\hline Muito Baixo & 0,20 & \\
\hline
\end{tabular}

Com a obtenção dos resultados da vulnerabilidade ambiental, em forma de mapas, foi possível fazer a sobreposição entre as duas dimensões da vulnerabilidade, ambiental e social. Para tanto, os níveis de vulnerabilidade ambiental encontrados foram nivelados com índices de (1.00), para muito alta vulnerabilidade; índice de $(0.80)$ para alta vulnerabilidade; índice de (0.60) para média vulnerabilidade; índice de (0.40) para baixa vulnerabilidade e índice de $(0.20)$ para muito baixa vulnerabilidade.

De posse desse resultado, foi realizada a média aritmética das duas etapas trabalhadas, obtendo-se o índice geral da vulnerabilidade socioambiental por setores censitários, utilizando a seguinte equação:

$\operatorname{IVSA}=\frac{(\mathrm{IVS}+\mathrm{IVA})}{2}$

IVSA $=$ Índice de vulnerabilidade socioambiental; IVS = Índice de vulnerabilidade social e IVA= Índice de vulnerabilidade ambiental.

O Quadro 3 demonstra a intersecção dos dados de vulnerabilidade social e ambiental, e os níveis correspondentes de vulnerabilidade socioambiental encontrada na área em estudo.

Quadro 3. Níveis de vulnerabilidade socioambiental a partir do cruzamento dos dados de vulnerabilidade ambiental e social.

\begin{tabular}{|l|l|l|l|l|l|}
\cline { 2 - 6 } \multicolumn{1}{c|}{} & \multicolumn{4}{c|}{ Vulnerabilidade Social } \\
\hline $\begin{array}{l}\text { Vulnerabilidade } \\
\text { Ambiental quanto } \\
\text { à inundação }\end{array}$ & Muito Alto & Alto & Médio & Baixo & Muito Baixo \\
\hline Muito Alto & IVSA Muito Alto & IVSA Muito Alto & IVSA Alto & IVSA Alto & IVSA Médio \\
\hline Alto & IVSA Muito Alto & IVSA Alto & IVSA Alto & IVSA Médio & IVSA Médio \\
\hline Médio & IVSA Alto & IVSA Alto & IVSA Médio & IVSA Médio & IVSA Baixo \\
\hline
\end{tabular}




\begin{tabular}{|l|l|l|l|l|l|}
\hline Baixo & IVSA Alto & IVSA Médio & IVSA Médio & IVSA Baixo & IVSA Baixo \\
\hline Muito Baixo & IVSA Médio & IVSA Médio & IVSA Baixo & IVSA Baixo & $\begin{array}{l}\text { IVSA Muito } \\
\text { Baixo }\end{array}$ \\
\hline
\end{tabular}

\section{$2^{a}$ Etapa: Diagnóstico da bacia/sub-bacia}

Partindo do pressuposto que o processo de urbanização gera consequências na drenagem urbana, para o diagnóstico das sub-bacias foram utilizados dois indicadores pertinentes a esse processo, a saber: porcentagem de impermeabilização e tempo de concentração.

Dessa forma, foi feito o levantamento da porcentagem de impermeabilização das sub-bacias delimitadas na pesquisa, fator que influencia diretamente na dinâmica fluvial. Essa análise resultou na classificação em quatro diferentes graus de impacto promovido pela urbanização, ${ }^{2}$ o qual pode ser observado na Tabela 1.

Tabela 1. Indicador para as sub-bacias: grau de impermeabilização

\begin{tabular}{llll}
\hline Grau de impermeabilização & $\begin{array}{l}\text { Nível de } \\
\text { impacto }\end{array}$ \\
\hline $\begin{array}{l}\text { Acima de } 60 \% \\
\text { impermeabilização }\end{array}$ & de & $\begin{array}{l}\text { Muito alto } \\
(1.00)\end{array}$ \\
\hline $\begin{array}{l}\text { Entre 25,01 e } 60 \% \\
\text { impermeabilização }\end{array}$ & de & Alto (0.80) \\
\hline $\begin{array}{l}\text { Entre 10,01 e 25\% } \\
\text { impermeabilização }\end{array}$ & de & Médio (0.60) \\
\hline Até 10\% de impermeabilização & Baixo (0.40) \\
\hline
\end{tabular}

Outro indicador trabalhado se refere ao tempo de concentração (tc), definido como o tempo necessário para que toda a bacia contribua para o escoamento superficial numa seção considerada.

Existem várias equações para a estimativa do tempo de concentração, algumas exigem poucos dados para sua alimentação, outras exigem uma quantidade maior de parâmetros. Nesse trabalho, foi utilizada a seguinte equação, que considera o grau de impermeabilização da bacia, visto que é um fator relevante em um estudo de macrodrenagem urbana:

2 baseado no gráfico da CWP (Center for Watersehd Protection) 2005. O detalhamento dessa
- Método de Germano:

$$
t c=18,628 \cdot \frac{L^{0,882}}{i m p^{0,272}}
$$

Em que:

$t c=$ tempo de concentração da bacia (min); $L=$ comprimento do talvegue principal $(\mathrm{km})$; imp $=$ porcentagem de área impermeável na bacia (\%)

Após o cálculo dos tempos de concentração de cada sub-bacia, dividiram-se os valores em quatro níveis, demonstrados na Tabela 2.

Tabela 2. Indicador para as sub-bacias: tempo de concentração

\begin{tabular}{ll}
\hline Tempo de concentração & $\begin{array}{l}\text { Nível de } \\
\text { impacto }\end{array}$ \\
\hline 3 a 20 minutos & $\begin{array}{l}\text { Muito alto } \\
(1.00)\end{array}$ \\
\hline 20,01 a 40 minutos & Alto $(0.80)$ \\
\hline 40,01 a 100 minutos & Médio $(0.60)$ \\
\hline Acima de 100 minutos & Baixo $(0.40)$ \\
\hline
\end{tabular}

\section{$3^{a}$ Etapa: Divisão e diagnóstico dos cursos d'água e suas margens}

Para composição do diagnóstico das margens, foi efetuada a divisão em três dimensões: uso e ocupação das margens, dimensão fluvial e dimensão ambiental. As referidas dimensões serão explicadas detalhadamente a seguir:

Dimensão uso e ocupação do solo das margens

Normalmente, o uso e a ocupação das margens causam impactos diretos nos rios, como já abordado anteriormente. Dessa forma, faz-se necessário o mapeamento das condições de suas margens, com foco no uso e ocupação. Através de imagem de satélite e

metodologia é constante em Rezende e Araújo (2015). 
uso de software tipo CAD, a ocupação e uso das margens dos cursos d'água foram delimitadas e mapeadas, por meio de dois mapas:

- Mapa de ocupação do solo das margens: possui a demarcação de trechos de ocupação, bem como análise, se eles se encontram em áreas de preservação permanente.

- Mapa de uso do solo das margens: há a demarcação dos usos das margens, através da seguinte tipologia:

residencial, comercial/serviços, industrial, e uso para turismo e lazer. Posteriormente estes usos, foram classificados conforme o nível de impacto ambiental que podem gerar. (conforme Tabela 3).

A seguir, apresenta-se a relação dos indicadores utilizados, baseado nos mapas confeccionados (Tabela 3).

Tabela 3. Indicadores da dimensão uso e ocupação do solo.

\begin{tabular}{|c|c|}
\hline Ocupação das margens & Nível de impacto \\
\hline Acima de $60 \%$ de ocupação & Muito alto (1.00) \\
\hline Entre 25,01 e $60 \%$ de ocupação & Alto $(0.80)$ \\
\hline Entre 10,01 e $25 \%$ de ocupação & Médio $(0.60)$ \\
\hline Até $10 \%$ de ocupação & Baixo $(0.40)$ \\
\hline Sem ocupação & Muito Baixo (0.20) \\
\hline Tipos de usos das margens & Nível de impacto \\
\hline $\begin{array}{l}\text { Uso de Muito Alto impacto } \\
\text { (acima de 55\% de uso industrial) }\end{array}$ & Muito Alto (1.00) \\
\hline $\begin{array}{l}\text { Uso de Alto impacto } \\
\text { (de } 20 \text { a } 55 \% \text { de uso industrial) }\end{array}$ & Alto $(0.80)$ \\
\hline $\begin{array}{l}\text { Uso de Médio impacto } \\
\text { (acima de } 50 \% \text { de uso turístico e/ou comercial e até } 50 \% \text { de uso } \\
\text { residencial) ou } \\
\text { (acima de } 50 \% \text { de uso turístico e/ou comercial; até } 30 \% \text { de uso } \\
\text { residencial e até } 20 \% \text { de uso industrial) }\end{array}$ & Médio (0.60) \\
\hline $\begin{array}{l}\text { Uso de Baixo impacto } \\
\text { (acima de } 50 \% \text { de uso residencial e até } 50 \% \text { de uso turístico e/ou } \\
\text { comercial) }\end{array}$ & Baixo $(0.40)$ \\
\hline Sem ocupação/uso & Muito Baixo $(0.20)$ \\
\hline
\end{tabular}

\section{Dimensão fluvial}

A dimensão fluvial se trata de aspectos físicos e funcionais do curso de água, como o desenvolvimento longitudinal, a seção transversal e a integridade morfológica. Para análise dessa dimensão, foi utilizada a metodologia elaborada por Cardoso (2012).

Para a autora, o desenvolvimento longitudinal é um indicador que integra a análise de três aspectos principais relacionados ao curso de água: 1- planta (largura e sinuosidade); 2- perfil (declividade) e 3-Continuidade.
Esses aspectos são justificados pela importância ao equilíbrio geomorfológico do canal fluvial. Em relação à seção transversal, foi feita a análise de três quesitos: 1- a configuração do seu leito e margens - forma; 2- a conectividade entre a calha, a planície fluvial e o lençol freático e 3- o tipo de revestimento empregado.

Já no tocante à integridade morfológica, o presente indicador se concentra nas condições de estabilidade das margens do curso de água, uma vez considerada a sua importância no contexto dos processos geomorfológicos. 
Segue a seguir a Tabela 4 que

demonstra todos os indicadores comentados.

Tabela 4. Indicadores da Dimensão fluvial

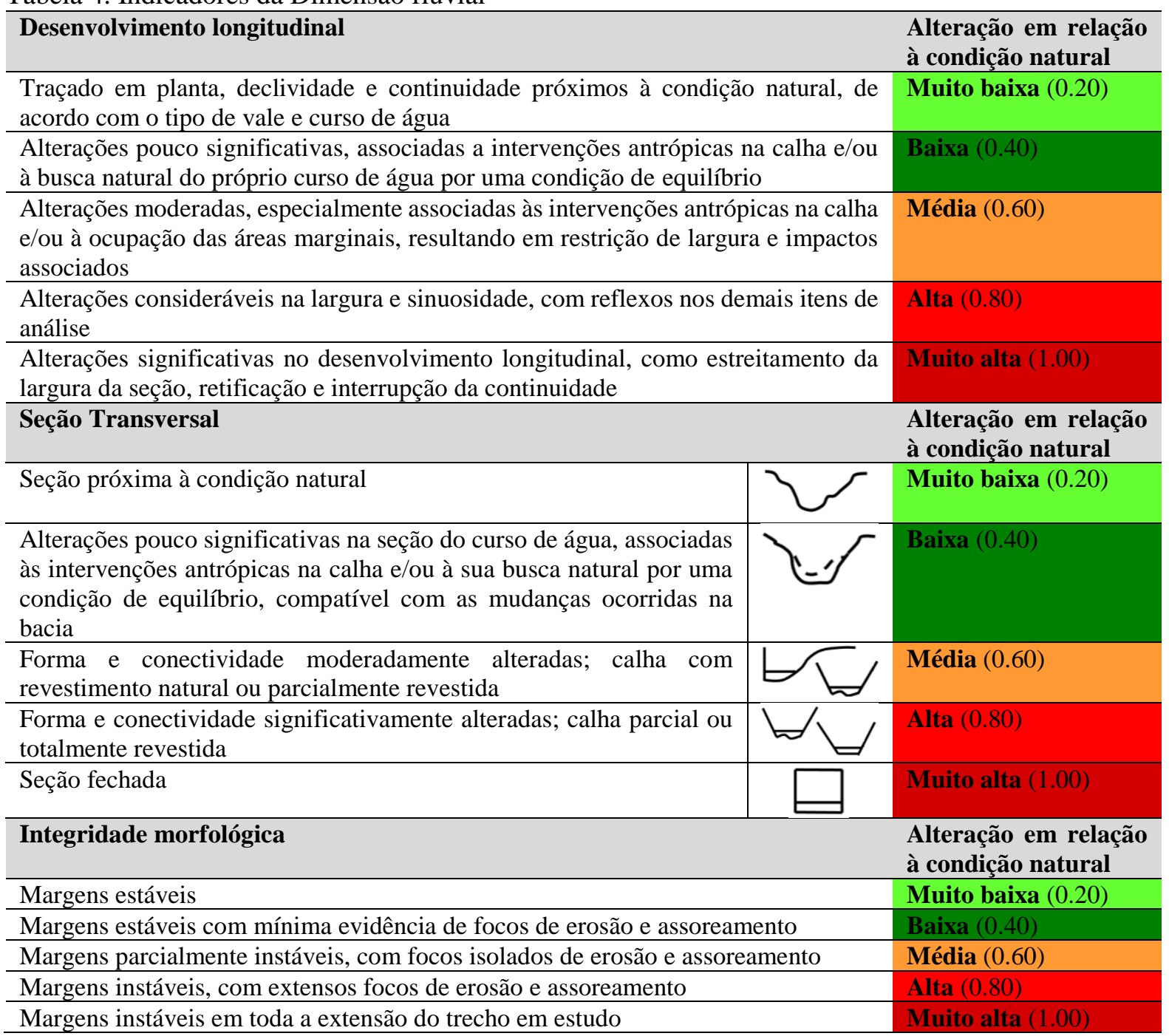

Fonte: adaptado de Cardoso (2012).

\section{Dimensão ambiental}

Para análise dessa dimensão, a referência também foi a metodologia elaborada por Cardoso (2012); onde, em termos ambientais, dois quesitos foram contemplados, a saber: a presença de vegetação ciliar e a qualidade da água.

A presença da vegetação ciliar ao longo dos cursos d'água assume papel importante nas dinâmicas dessas áreas, sendo que as alterações e retirada da mesma podem causar diversas consequências. Dessa forma, essas alterações foram verificadas in loco, utilizando-se como parâmetro a presença natural de vegetação em cada trecho analisado.

Em relação à qualidade da água, devido à falta de dados em alguns trechos dos rios, a análise do presente indicador se pauta em Cardoso e Baptista (2009) e assume caráter superficial, pautado na observação qualitativa do curso de água quanto à presença de esgotos e resíduos sólidos, por meio de visitas a campo (Tabela 5). Já para os rios Araguaia e Garças, as classes de degradação foram definidas por meio de análise quantitativa, por meio do índice de qualidade 
da água (IQA) divulgado pelos relatórios de monitoramento da Secretaria de Estado do Meio Ambiente (SEMA).

O IQA é calculado pelo produto ponderado da qualidade da água correspondente a nove parâmetros: oxigênio dissolvido, Escherichia coli, $\mathrm{pH}$, DBO5, nitrogênio nitrato, fósforo total, turbidez, sólidos totais e temperatura de desvio. (SEMA
2014). A classificação do IQA segue cinco níveis: ótima, boa, média, ruim e muito ruim, que transferidas para a presente metodologia referem-se ao níveis: muito baixa, baixa, média, alta e muito alta.

$\mathrm{Na}$ Tabela 5, encontram-se as condições de referência relacionadas à dimensão ambiental, assim como a descrição de seus possíveis cenários de alteração.

Tabela 5. Indicadores da Dimensão ambiental

\begin{tabular}{ll}
\hline Qualidade da água & $\begin{array}{l}\text { Alteração em relação } \\
\text { à condição natural }\end{array}$ \\
\hline IQA muito bom / Ausência de esgotos e/ou resíduos sólidos & Muito baixa (0.20) \\
\hline IQA bom / Pequena presença de esgotos e/ou resíduos sólidos & Baixa $(0.40)$ \\
\hline IQA médio / Moderada presença de esgotos e/ou resíduos sólidos & Média (0.60) \\
\hline IQA ruim / Considerável presença de esgotos e/ou resíduos sólidos & Alta (0.80) \\
\hline IQA muito ruim / Significativa presença de esgotos e/ou resíduos sólidos & Muito alta (1.00) \\
\hline Presença de mata ciliar/vegetação & $\begin{array}{l}\text { Alteração em relação } \\
\text { à condição natural }\end{array}$ \\
\hline Presença de vegetação próxima à condição natural & Muito baixa (0.20) \\
\hline Alterações pouco significativas quanto à presença de vegetação & Baixa $(0.40)$ \\
\hline Alterações moderadas quanto à presença de vegetação & Média (0.60) \\
\hline Alterações consideráveis quanto à presença de vegetação & Alta (0.80) \\
\hline Alterações significativas quanto à presença de vegetação & Muito alta (1.00) \\
\hline
\end{tabular}

Fonte: adaptado de Cardoso (2012).

Para cada trecho do canal fluvial analisado, foi preenchida uma tabela com todos os indicadores, a exemplo do caso hipotético apresentado pela tabela 6 . Para o níveis encontrados - muito baixo, baixo, médio, alto e muito alto - foram impostos valores, respectivos de $-0.20 ; 0.40 ; 0.60 ; 0.80$ e 1.00 - o que possibilita, através de média aritmética, encontrar valores para o resultado parcial de cada dimensão e o resultado geral para cada trecho do canal fluvial, conforme Tabela 6 que segue.

Tabela 6. Representação gráfica das condições encontradas em um trecho hipotético

\begin{tabular}{|c|c|c|c|c|c|c|}
\hline \multirow{2}{*}{$\begin{array}{l}\text { Dimensão } \\
\text { Fluvial }\end{array}$} & \multirow[t]{2}{*}{ Indicadores } & \multicolumn{5}{|c|}{ Alteração em relação à condição natural } \\
\hline & & $\begin{array}{c}\text { Muito Baixa } \\
0.20\end{array}$ & $\begin{array}{l}\text { Baixa } \\
0.40\end{array}$ & $\begin{array}{c}\text { Média } \\
0.60\end{array}$ & $\begin{array}{l}\text { Alta } \\
0.80\end{array}$ & $\begin{array}{c}\text { Muito Alta } \\
1.00\end{array}$ \\
\hline & Des. Longitudinal & & & & & \\
\hline & Seção transversal & & & & & \\
\hline & Integridade Morfológica & & & & & \\
\hline & Resultado parcial & & & & & \\
\hline \multirow[t]{3}{*}{ Ambiental } & Qualidade da água & & & & & \\
\hline & Presença de mata ciliar & & & & & \\
\hline & Resultado parcial & & & & & \\
\hline \multirow[t]{3}{*}{ Uso e ocupação } & Ocupação das margens & & & & & \\
\hline & Uso das margens & & & & & \\
\hline & Resultado parcial & & & & & \\
\hline \multirow{5}{*}{$\begin{array}{l}\text { Bacia e sub- } \\
\text { bacias }\end{array}$} & Impermeabilização & & & & & \\
\hline & Tempo de concentração & & & & & \\
\hline & Vulnerabilidade Socioambiental & & & & & \\
\hline & Resultado parcial & & & & & \\
\hline & Aspecto geral & & & & & \\
\hline
\end{tabular}


Após a análise de todos os indicadores, foi confeccionado um mapa sobre imagem satélite com a indicação do nível de alteração em relação à condição natural e consequentemente de intervenção por trecho, o qual poderá servir de norteador para planejamento das margens dos rios.

\section{Resultados e discussão}

\section{$1^{a} \quad$ Etapa: Diagnóstico $\quad d a$ Vulnerabilidade socioambiental}

No tocante à vulnerabilidade socioambiental da área em estudo, foram analisados o Índice de Vulnerabilidade Social (IVS) e o Índice de Vulnerabilidade Ambiental (IVA). O primeiro, apresentou valores "muito baixos, baixos e médios", já o segundo, apresentou índices "muito baixos, baixos, médio, altos e muito altos". Em seguida, mediante a sobreposição desses dois índices, foram encontrados índices socioambientais "muito baixos, baixos, médios e altos". 3

Ressalta-se que a sobreposição de mapas produzidos com apoio no Índice de Vulnerabilidade Social e o mapa de vulnerabilidade à inundação, possibilitou a identificação e localização dos espaços onde ocorrem coincidências de riscos e vulnerabilidades - sociais e ambientais representados graficamente pelo Mapa de Vulnerabilidade Socioambiental. (Figura 4)

Com base na Figura 4 a seguir, é possível visualizar os níveis muito baixo, baixo, médio e alto da vulnerabilidade socioambiental na área de estudo e como ela se distribui. A população exposta ao nível alto se encontra às margens dos rios Araguaia e Figura 4. Mapa de Vulnerabilidade Socioambiental
Garças. Nesses locais, mesmo havendo vulnerabilidade social baixa, os moradores estão submetidos à exposição física e a fenômenos naturais potencializados pela ação humana, como é o caso das inundações.

Como os níveis encontrados para o IVS, foram "muito baixos, baixos e médios", percebe-se que os indicadores sociais não foram determinantes para os níveis médios e altos encontrados no Índice de Vulnerabilidade Socioambiental (IVSA), mas sim os indicadores presentes no IVA.

É possível, dessa maneira, presumir que mesmo exposta a riscos ambientais, a população pode ter maiores condições de resiliência a eventos extremos, uma vez que os resultados socioeconômicos e de infraestrutura foram relativamente satisfatórios. Contudo, tal resultado não prescinde que medidas mitigatórias e de prevenção às ocupações das áreas de risco sejam implementadas pelo Poder Público.

\footnotetext{
${ }^{3}$ Uma descrição mais detalhada dos resultados encontrados para a etapa de diagnóstico da
}

Vulnerabilidade Socioambiental pode ser encontrada em Rezende (2015). 


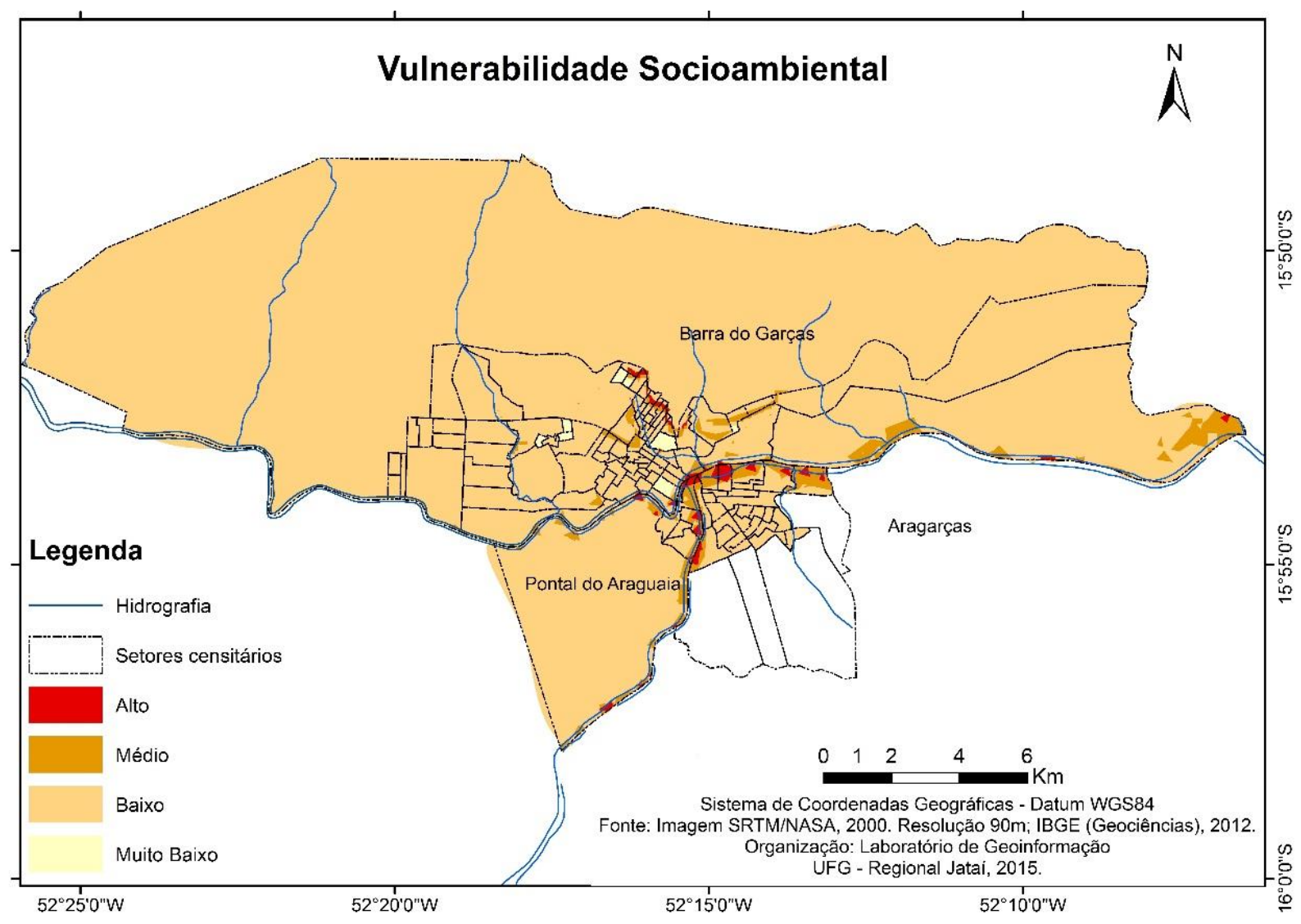

\section{$2^{a}$ Etapa: Diagnóstico da bacia/sub-bacia}

Inicialmente, foi feita a delimitação das sub-bacias, as quais foram extraídas a partir do modelo digital de elevação do TOPODATA (Banco de dados geomorfométricos do Brasil) disponibilizado pelo Instituto Nacional de Pesquisas Espaciais (INPE), bem como através do software TERRAVIEW, utilizando o plugin TERRAHIDRO.

Para melhor compreensão, as subbacias foram numeradas, totalizando 55. O objetivo é a demarcação dessas sub-bacias na área urbana dos municípios, contudo há algumas localizadas nos setores mais periféricos da área de estudo e ultrapassam tal limite, ocupando também áreas rurais. ${ }^{4}$

\footnotetext{
4 Uma descrição mais detalhada do resultados encontrados para a etapa de diagnóstico das sub-
}

Com efeito, de acordo com a Figura 5, das 55 sub-bacias, 7 delas apresentam nível alto, as quais coincidem com o setor central das cidades de Barra do Garças-MT e Aragarças - GO, o que é um fato comum aos setores mais centrais de cidades, que normalmente apresentam maiores índices de impermeabilização.

Observou-se também que a maior parte da área urbanizada de Pontal do Araguaia - MT está inserida em sub-bacias com nível médio de impermeabilização (subbacias 39 e 48); e, da mesma forma, as subbacias 7, 9, 10 e 53 também possuem nível médio de impermeabilização. Já as sub-bacias que estão na área periférica, são aquelas que apresentaram menores taxas de impermeabilização.

bacias pode ser encontrada em Rezende e Araújo (2015). 
Figura 5. Grau de impermeabilização das sub-bacias

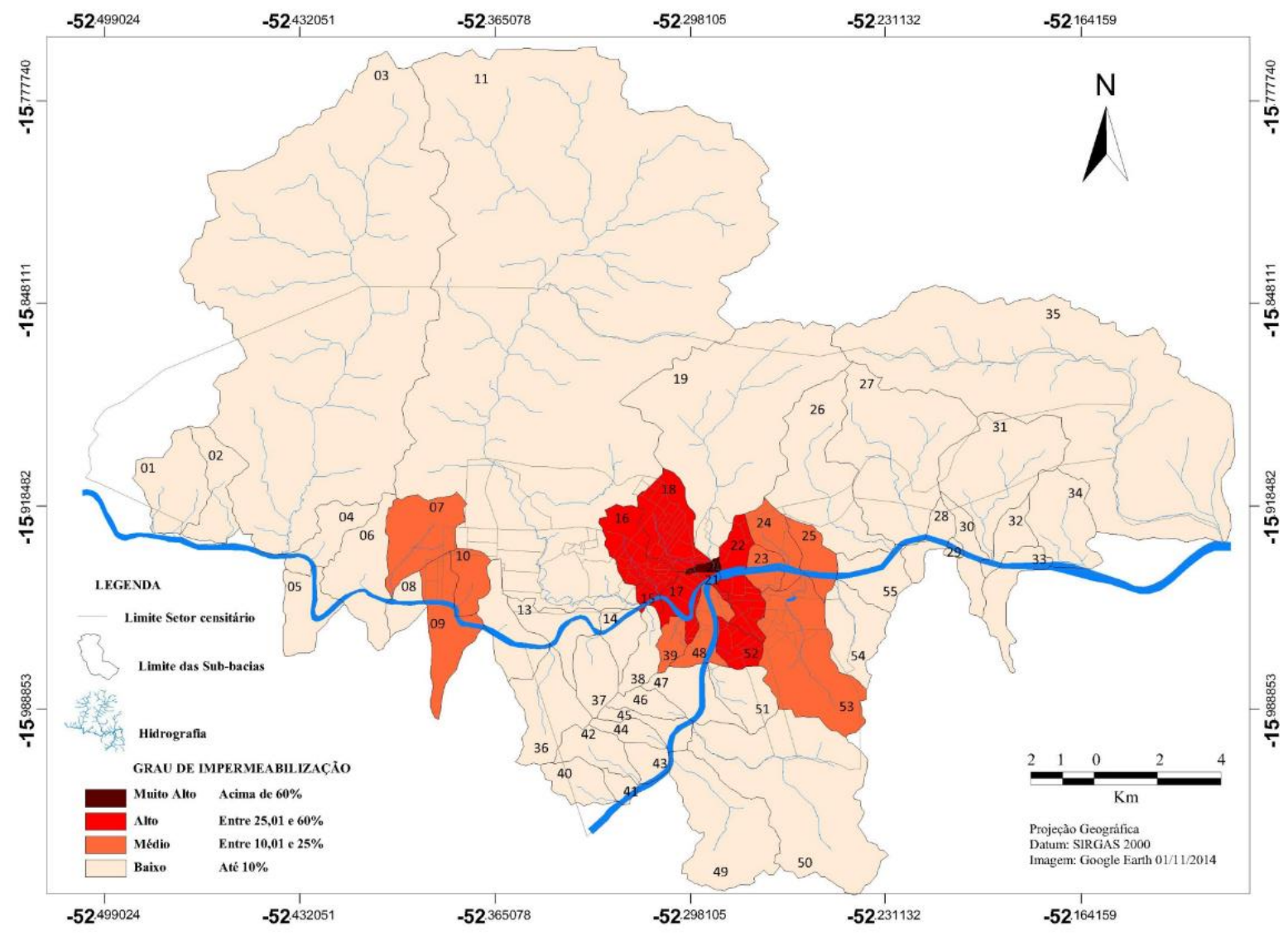

Fonte: Rezende e Araújo (2015).

Diante do exposto, verifica-se que o planejamento urbano dessas cidades deve considerar o impacto da expansão urbana, especialmente de futuros loteamentos sobre a drenagem de águas pluviais, visto que, nas áreas já urbanizadas o grau de impermeabilização das sub-bacias apresentou nível alto e médio, o que acarreta aumento do volume do escoamento superficial e aumento do pico da vazão máxima das cheias.

No tocante ao tempo de concentração, verifica-se que as pequenas sub-bacias apresentaram menores valores $\mathrm{e}$ consequentemente maiores níveis - alto e muito alto, seguidas pelas bacias médias, como é o caso das sub-bacias $26,31,53,54$ e 55 , conforme Figura 6. As sub-bacias que apresentaram maiores valores de tempo de concentração são aquelas maiores, periféricas e que possuem uma área permeável considerável (nível baixo). 
Figura 6. Mapa com a demarcação dos tempos de concentração estimados para cada sub-bacia

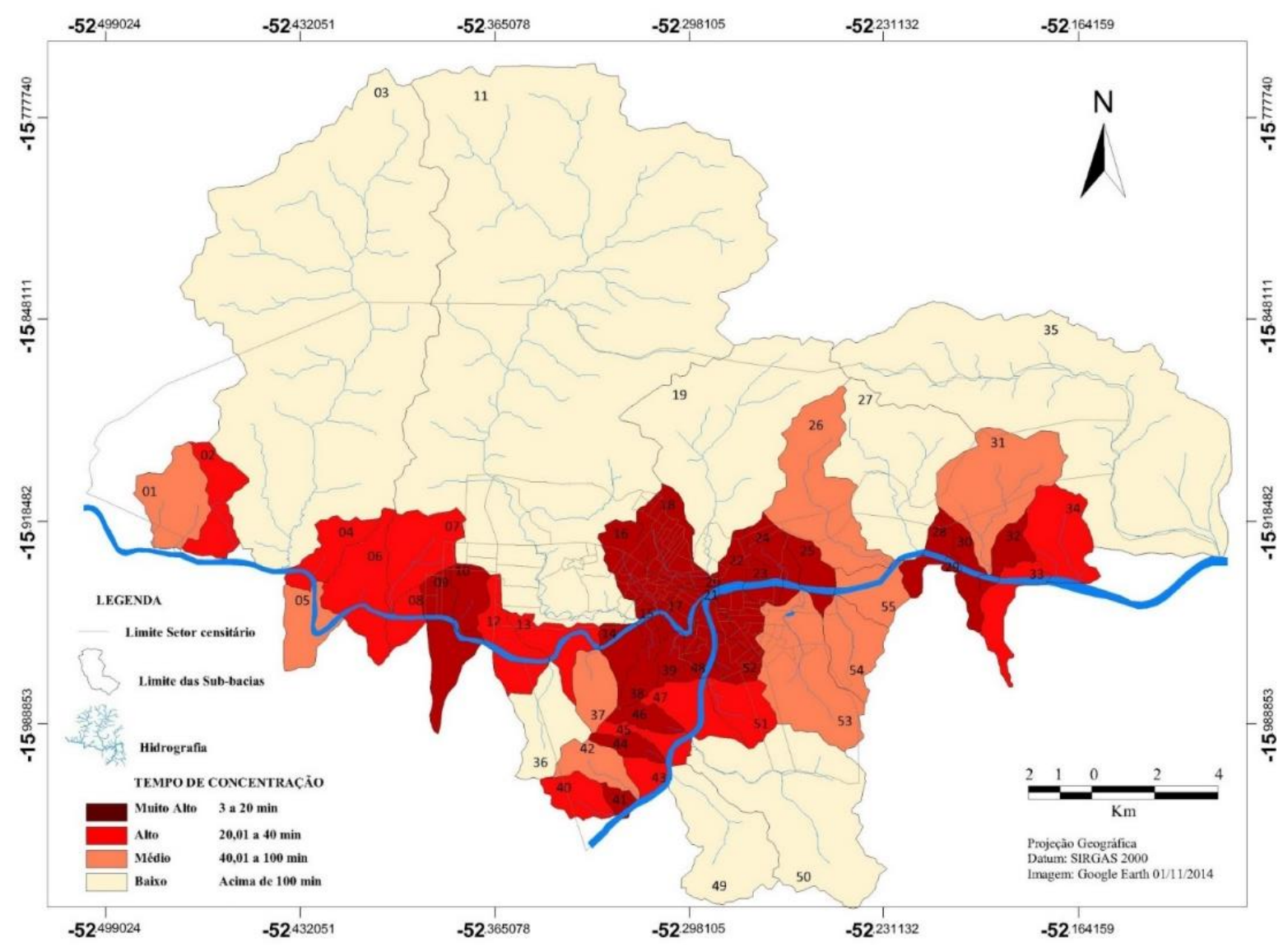

Fonte: Rezende e Araújo (2015).

Ainda de acordo com a Figura 6, verifica-se que todas as sub-bacias que margeiam o rio das Garças e o rio Araguaia apresentaram baixos valores de tempo de concentração, o que pode contribuir significamente para o aumento na frequência e no volume das inundações dessas áreas.

Dessa forma, reforça-se a importância da adoção de medidas não-estruturais, como legislação de uso do solo, com regras e incentivo para aumento de áreas permeáveis em lotes e a regulação da expansão urbana de futuros loteamentos, visto que há uma estreita relação entre $o$ aumento de áreas impermeabilizadas e a redução do tempo de concentração.

\section{$3^{a}$ Etapa: Divisão e diagnóstico dos cursos d'água e suas margens}

A última etapa da aplicação da metodologia se concentra no diagnóstico das margens dos cursos d'água acerca de suas condições fluviais, ambientais e dos aspectos urbanos (uso e ocupação do solo). Esses dados, adicionados aos resultados já demonstrados das sub-bacias, possibilitaram um diagnóstico completo de cada trecho.

$\mathrm{O}$ rio das Garças foi dividido em 4 trechos e o rio Araguaia em 6 trechos. A Figura 7 demonstra a divisão de trechos adotada. 
Figura 7 - Trechos divididos para o Rio Araguaia e das Garças

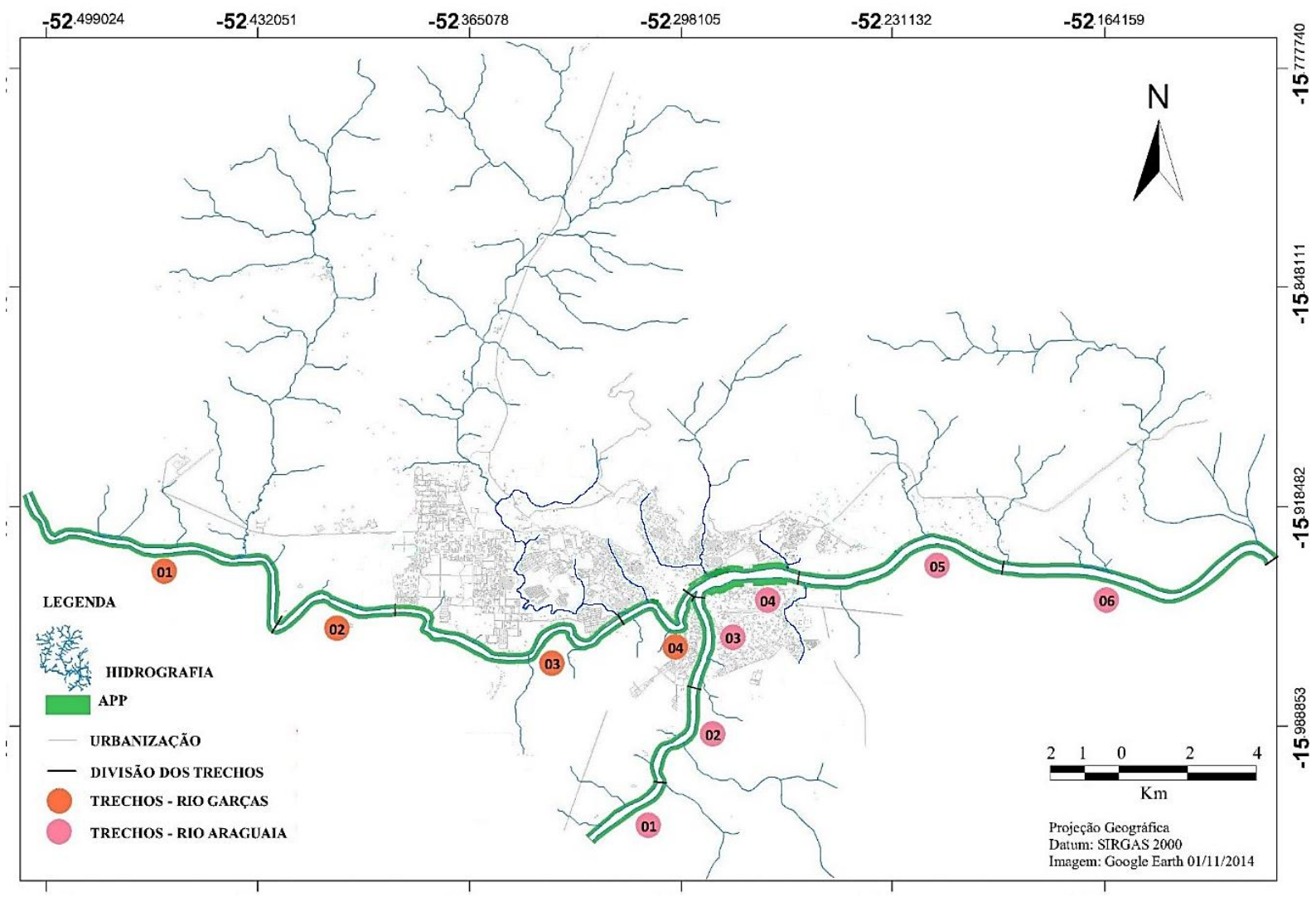

Fonte: Elaborado pela autora.

Em todos os trechos foram demarcadas as áreas de preservação permanente e é necessário que a linha do curso d'água seja fielmente retratada. Para maior detalhamento, as linhas dos cursos de água foram desenhadas manualmente sobre imagem de satélite do software Google Earth.

Posteriormente, foram delimitadas as medidas de APP, considerando como tal a largura de 100 metros às margens dos rios Araguaia e das Garças. Isso se deve em razão do Código Florestal brasileiro estabelecer que, nos rios que tenham entre 50 e 200 metros de largura, a APP seria de 100 metros. A exceção é o trecho 04 do rio Araguaia, o qual, após a confluência com o rio das Garças, possui locais com largura superior a 200 metros. Nesses locais pontuais, a APP é de 200 metros.

Optou-se por aplicar a metodologia em cada margem do rio, separadamente. Isso porque, após cuidadosa análise dessas margens, verificou-se que possuem consideráveis disparidades e, dessa maneira, analisá-las em conjunto poderia não conduzir a um resultado eficaz.

Para tanto, foram verificadas in loco, a situação das margens no final do mês de abril e início do mês de maio de 2015, correspondente ao início do período de estiagem. Seguem abaixo os resultados obtidos para cada corpo hídrico.

\section{Rio das Garças}

\section{Dimensão Fluvial}

Na Dimensão Fluvial, foram observados três indicadores, a saber: desenvolvimento longitudinal, seção transversal e integridade morfológica. 
No tocante ao desenvolvimento longitudinal, foi feito um comparativo do traçado do rio através de imagem satélite landsat do software Google Earth de 2003 a 2014 e pouca mudança foi encontrada, sendo classificado com nível de Muito Baixa alteração em relação à condição natural. A exceção é o trecho 03, que apresentou alteração em seu traçado.

Salienta-se que a importância desse indicador transcende a dimensão de ordem física, relacionando-se às condições de funcionamento do canal, em especial no tocante ao equilíbrio geomorfológico.

Em relação a condição da seção transversal, que denota a integração de três itens, forma, conectividade e o tipo de revestimento empregado, verificou-se que, em todos os trechos, a calha do rio é natural, sem intervenções em seu revestimento.

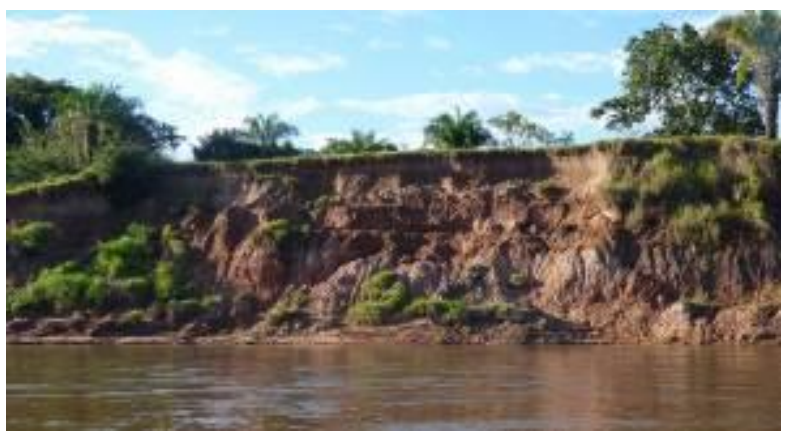

Figura 8. Erosão na margem esquerda do trecho 03 Fonte: Foto da autora (2015).

Na dimensão fluvial, esse indicador foi o que apresentou o nível mais crítico e, como consequência, observou-se o assoreamento do rio, o qual também foi observado no trechos 03 e 04 . Salienta-se que o processo de assoreamento de um rio se encontra intimamente relacionado aos processos erosivos, uma vez que são esses que fornecem os materiais que, ao serem transportados e depositados, dão origem ao assoreamento.

A seguir, relatam-se as condições encontradas na dimensão ambiental, abrangendo a presença de mata ciliar e qualidade da água.

\section{Dimensão Ambiental}

Contudo, nos trechos 03 e 04, as interferências antrópicas geraram alterações na seção (pouco significativas). No trecho 03, há pontos em que a ocupação e retirada de vegetação alteraram a conectividade. Já, no trecho 04, a erosão das margens provoca o assoreamento do rio e consequentemente a alteração da seção do mesmo. Tal fator está diretamente relacionado à integridade morfológica das margens.

Quanto ao indicador integridade morfológica, relacionado à estabilidade da margem, os trechos 03 e 04 foram classificados com nível alto de alteração em relação à condição natural. Tal resultado se deve aos diversos pontos de erosão demarcados e encontrados no local (Figuras 8 e 9). Outrossim, é interessante ressaltar que o processo erosivo ativo é responsável por alta produção de sedimento, também observado no local.

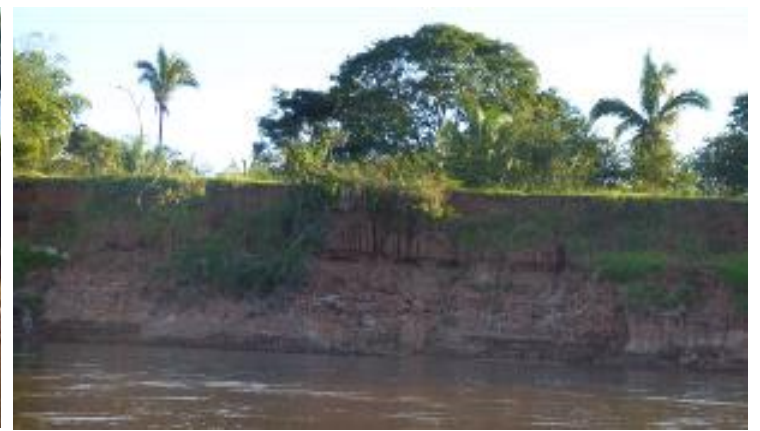

Figura 9. Erosão na margem direita do Trecho 04 Fonte: Foto da autora (2015).

No tocante ao indicador Presença de mata ciliar, analisou-se, através de imagem satélite, o quanto as margens estavam desmatadas e, in loco, também foram observadas as alterações da vegetação nativa por outros tipos de vegetação.

Verificou-se que o uso agrícola impacta igualmente na retirada de vegetação nativa. Tal fato pode ser observado no trecho 02, que apesar de não estar em área urbana consolidada, estava com sua mata ciliar bastante desmatada. Nesse trecho, a vegetação nativa foi substituída por gramíneas cultivadas para formação de pastagem de animais.

Os trechos 03 e 04, inseridos em área com maior urbanização, também estavam altamente impactados, gerando níveis de alteração Alto e Muito Alto. Nesses trechos, 
também foram observados determinados locais onde houve a substituição da vegetação nativa por exótica.

Ressalta-se que a vegetação marginal ao longo de cursos de água assume papel significativo no que tange à proteção de suas margens, ao controle de processos de erosão, à melhoria da qualidade da água e ao aumento da diversidade de habitats. Nos trechos 03 e 04, observou-se a relação direta entre a retirada da vegetação e a presença de erosão, denotando o quanto a conservação da mata ciliar é preponderante para a estabilidade de suas margens.

Quanto ao indicador Qualidade da Água, foram verificados os níveis de IQA (Índice de Qualidade da Água) disponibilizados pelos Relatórios de Qualidade Ambiental da SEMA. No rio das Garças, há dois pontos de monitoramento, sendo que um deles se encontra no trecho 01 , e outro bem a jusante, na foz do rio das Garças, no trecho 04. Para ambos, o IQA obtido foi BOM o que, transferido para a metodologia do presente trabalho, refere-se ao nível BAIXO, no tocante a alteração da condição natural. Para maior coerência, os trechos 02 e 03 também foram classificados com nível baixo.

\section{Dimensão uso e ocupação do solo}

Essa dimensão contém dois indicadores: ocupação das margens e tipos de usos das margens. Para o indicador da ocupação das margens, foram mapeadas as áreas de ocupação nas APPs. Tal demarcação foi feita sobre imagem satélite, utilizando o software AUTOCAD. Posteriormente, foram calculadas as porcentagens de ocupação para cada trecho.

Por estar em área mais urbanizada, o trecho 04 apresentou em suas margens, esquerda e direita, nível alto e médio, respectivamente, correspondendo aos níveis mais altos encontrados. Nesse trecho, a APP não foi respeitada e extensas áreas foram ocupadas. Observaram-se também ocupações recentes, ou ainda em construção, o que denota que o desrespeito à APP ainda continua.

No tocante ao uso do solo das margens, foram percorridas as vias de acesso aos locais onde havia ocupação da APP, e os tipos de uso foram mapeados. Os resultados obtidos são observados na Figura 10.

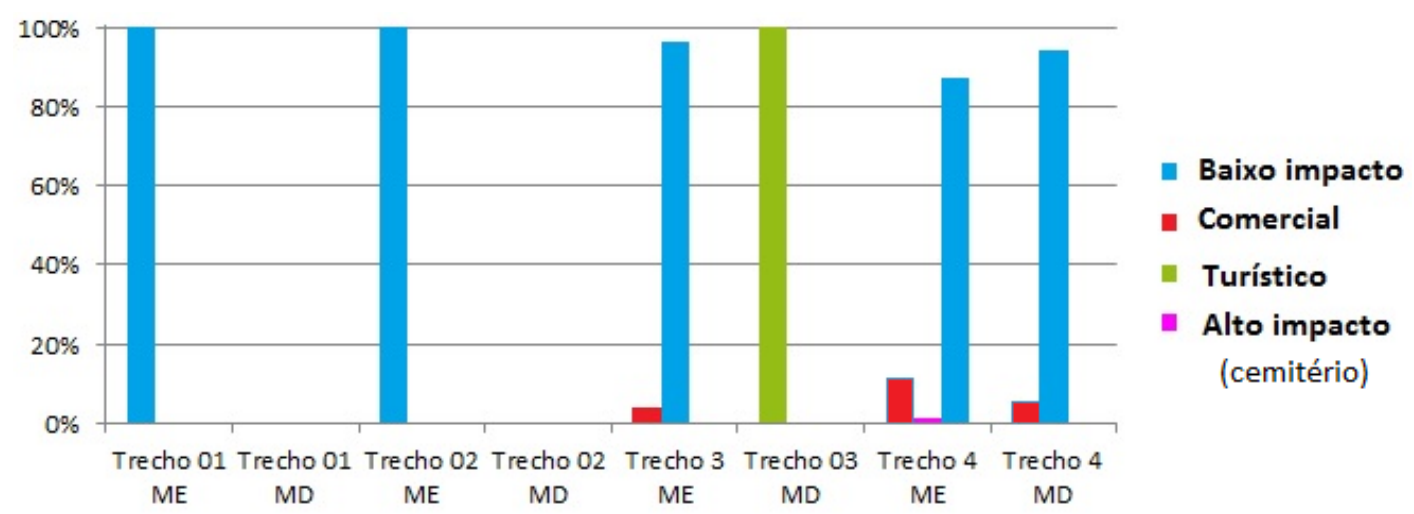

Figura 10. Porcentagem de usos nas margens do rio das Garças.

Verifica-se, na Figura 10, que em todos os trechos, a maioria dos usos são de baixo impacto (residenciais, institucionais, pavimentação, etc.). A exceção se refere à margem direita do trecho 03, com nível médio. Tal classificação se deve ao uso turístico da praia das Araras, no Pontal do Araguaia, a qual está presente nesse trecho.
Mesmo tendo seu uso turístico potencializado nos meses de julho e agosto, é importante que seja feito um controle dos impactos provocados, incluindo-se a educação ambiental e o plano de resíduos sólidos dos locais. Como exemplo de impactos, cita-se a intensa movimentação em época de temporada, uma vez que gera resíduos sólidos $\mathrm{e}$, consequentemente, poluição das águas. 
Todos os níveis dos indicadores descritos foram somados aos valores das subbacias e se obteve média aritmética para composição do resultado geral do presente diagnóstico, conforme descrito a seguir.

\section{Resultado Geral}

Para o resultado geral trecho a trecho, foi adicionado os dados das sub-bacias: o grau de impermeabilização, o tempo de concentração e a vulnerabilidade socioambiental. Como os trechos estão inseridos, em várias sub-bacias, determinouse a classificação do nível predominante na maioria do trecho. No tocante à vulnerabilidade socioambiental, também foi adotado o mesmo procedimento.

As sub-bacias que margeiam o rio das Garças possuem, em sua maioria, baixo grau de impermeabilização, exceto pelo trecho 04 onde se tem um alto grau de impermeabilização, visto que essas áreas apresentam alta densidade, tanto em Barra do Garças (margem esquerda) como em Pontal do Araguaia (margem direita). Em relação ao tempo de concentração, as sub-bacias apresentaram nível alto e muito alto, por se tratarem de sub-bacias pequenas.

Quanto à vulnerabilidade socioambiental, somente o trecho 04, na foz do rio das Garças, apresentou pequenas áreas de vulnerabilidade socioambiental alta, influenciadas pelas manchas de inundação de frequência muito alta. Contudo, como esses trechos são pouco extensos e isolados, foi demarcado respectivamente nível baixo e médio para margem esquerda e direita, níveis que cobrem a maioria do trecho.

Seguem, no Quadro 4 e 5, os resultados do trecho 03 e 04 do rio das Garças, os quais apresentaram uma maior alteração em relação à condição natural.

Quadro 4. Resultado dos indicadores para o Trecho 03 do rio das Garças.

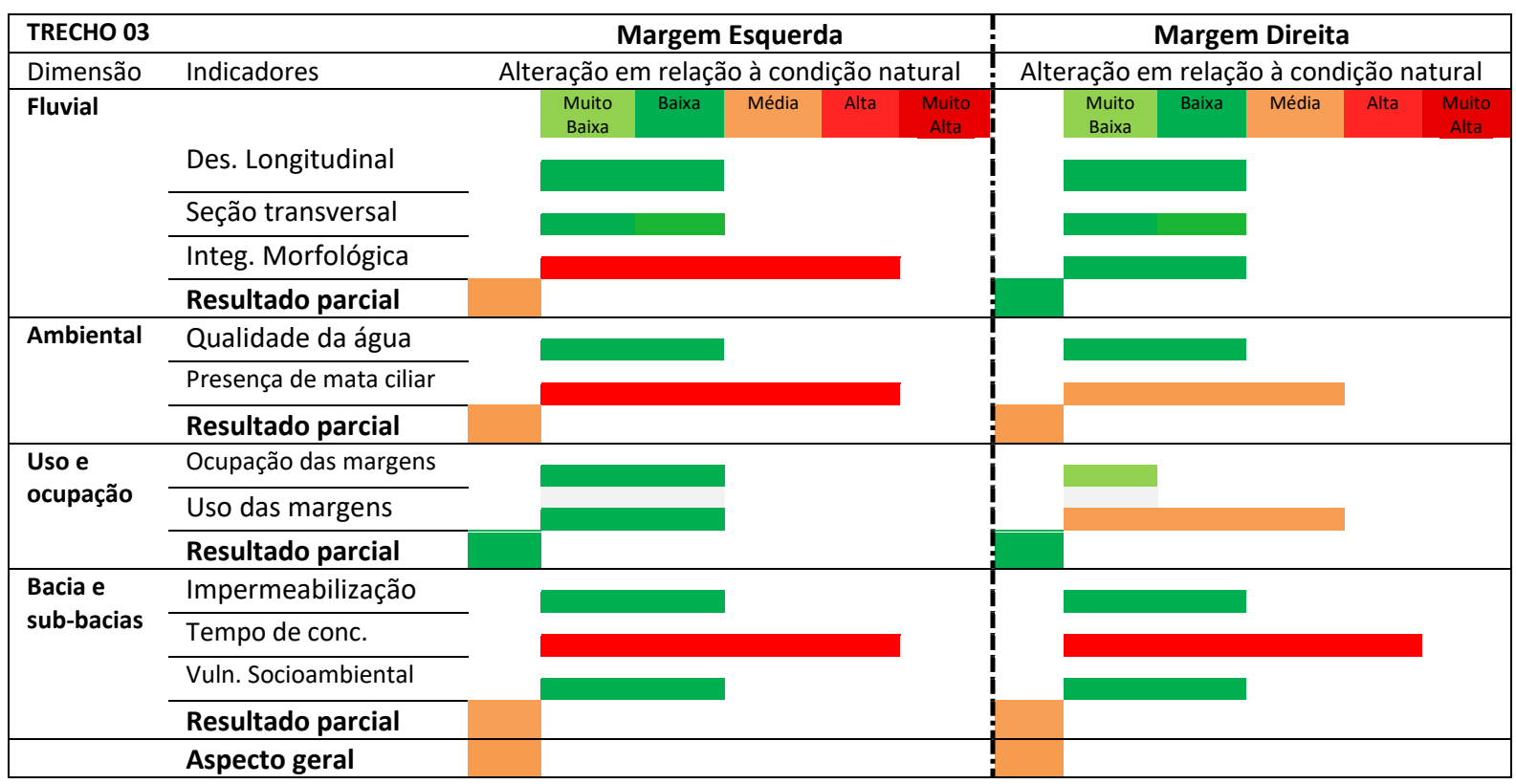

Quadro 5. Resultado dos indicadores para o Trecho 04 do rio das Garças.

\begin{tabular}{|c|c|c|c|c|c|c|c|c|c|c|c|}
\hline \multirow{2}{*}{$\begin{array}{l}\text { TRECHO } 04 \\
\text { Dimensão }\end{array}$} & \multirow[b]{2}{*}{ Indicadores } & \multicolumn{5}{|c|}{ Margem Esquerda } & \multicolumn{5}{|c|}{ Margem Direita } \\
\hline & & \multicolumn{5}{|c|}{ Alteração em relação à condição natural } & \multicolumn{5}{|c|}{ Alteração em relação à condição natural } \\
\hline \multirow[t]{3}{*}{ Fluvial } & & $\begin{array}{l}\text { Muito } \\
\text { Baixa }\end{array}$ & Baixa & Média & Alta & $\begin{array}{l}\text { Muito } \\
\text { Alta }\end{array}$ & $\begin{array}{c}\text { Muito } \\
\text { Baixa }\end{array}$ & Baixa & Média & Alta & $\begin{array}{l}\text { Muito } \\
\text { Alta }\end{array}$ \\
\hline & Des. Longitudinal & & & & & & & & & & \\
\hline & Seção transversal & & & & & & & & & & \\
\hline
\end{tabular}




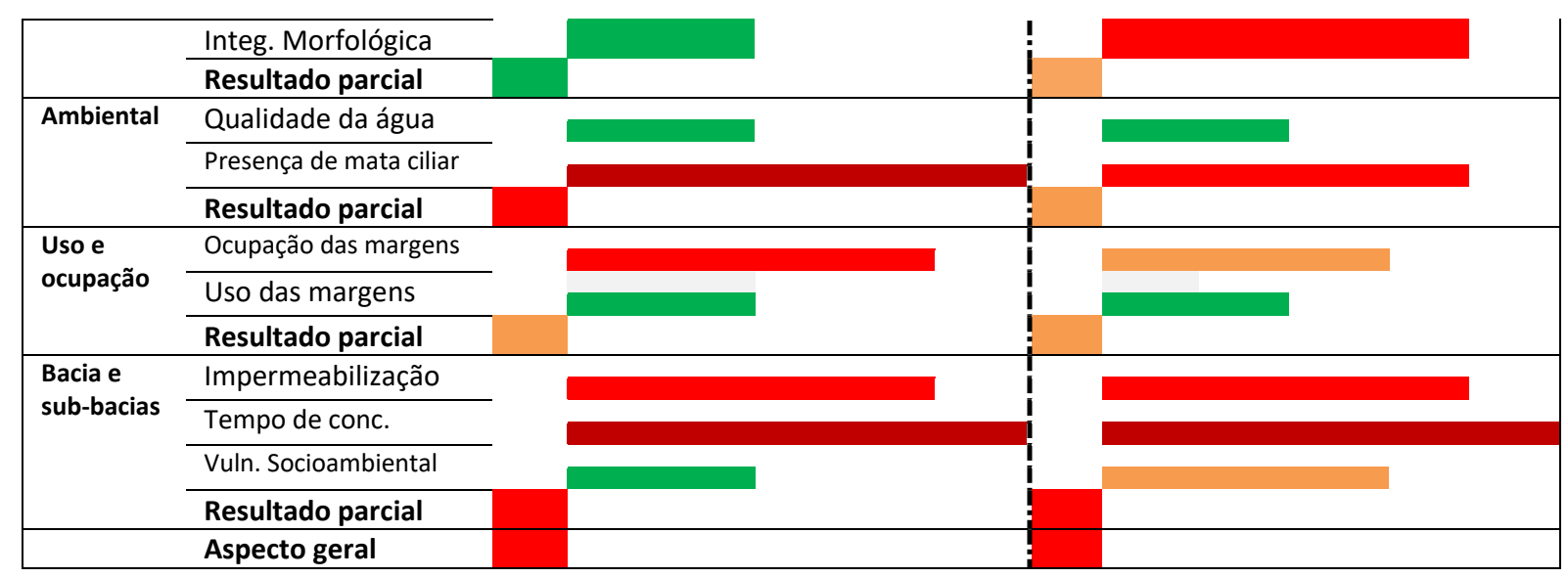

Verifica-se que os trechos 03 e 04 são os mais impactados no tocante à estabilidade das margens e a presença de mata ciliar. Há uma relação direta entre esses dois indicadores, pois os locais onde houve mais retirada de mata ciliar - seja por substituição por vegetação exótica, gramíneas ou por ocupações de edificação - foram aqueles que mais apresentaram extensos focos de erosão e, consequentemente assoreamento do rio.

O trecho 04, em específico, está sub-bacias bem concentração pequenos e possui, em suas margens, pontos de inundações com frequência muito alta. Tais aspectos denotam que políticas públicas devem ser intensificadas para o manejo adequado das águas pluviais, bem como a regulação e fiscalização do uso e ocupação sustentável do solo.

Os trechos 01 e 02 , por não estarem totalmente urbanizados, são passíveis de medidas preventivas de proteção das APPs. O primeiro trecho demonstrou estar um pouco mais preservado, porém o trecho 02 aparenta sinais de degradação de suas margens, principalmente no que concerne à supressão da mata ciliar. Esses trechos obtiveram nível baixo de alteração em relação à condição natural, exceto a margem esquerda do trecho 02, que resultou em nível médio de alteração.

\section{Rio Araguaia}

\section{Dimensão Fluvial}

Em relação ao desenvolvimento longitudinal, ao se fazer o comparativo das imagens satélites do software Google Earth, os únicos trechos que apresentaram alteração foram os trechos 02 e 04 . O trecho 02 apresentou pequena variação na sua largura, considerando suas duas margens e, portanto, foi classificado como de nível baixo.

Já o trecho 04 apresentou considerável alteração no seu traçado. A hipótese levantada é que a urbanização da beira-rio, em Aragarças, e principalmente a canalização das águas pluviais com despejo próximo à praia, podem ter contribuído para alterações no local. Comparando as imagens históricas, é significativa a mudança ocorrida (Figura 11).

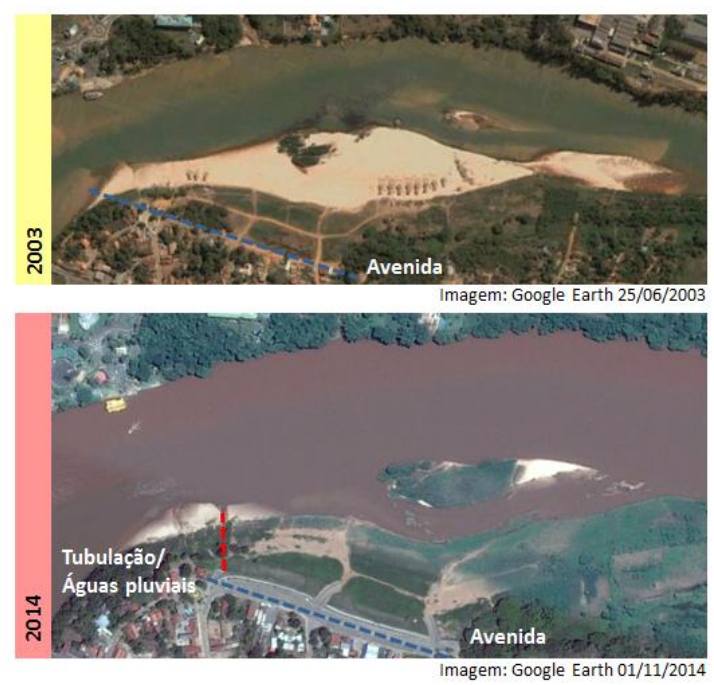

Figura 11. Alterações sofridas no trecho 04 do Rio Araguaia

No tocante à seção transversal, essa interferência antrópica, no trecho 04, também 
gerou alterações pouco significativas na seção do curso de água, produzindo o alargamento do canal, sendo classificada como alteração em relação à condição natural de nível baixo. Os demais trechos foram classificados com nível muito baixo, haja vista que as seções são todas naturais, sem intervenção no tipo de revestimento das mesmas.

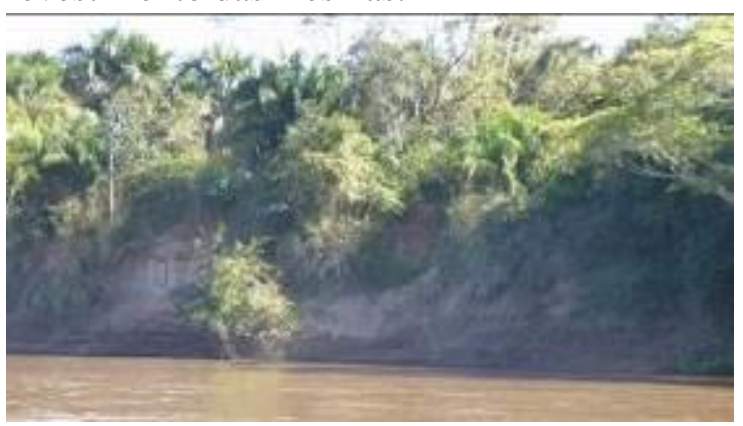

Figura 12. Erosão na margem esquerda do trecho 02 Rio Araguaia.

Fonte: Foto da autora (2015).

Salienta-se que foi verificada, também, a retirada da vegetação em alguns pontos onde foram construídos pequenos portos e vias de acesso para embarcações pequenas, contribuindo para instabilidade nos taludes e desenvolvimento de erosões.

Os sulcos erosivos representam um problema preocupante nesses trechos, uma vez que, com o passar do tempo, tendem a aumentar em extensão e intensidade. Ressaltase que, a retirada da vegetação contribui sistematicamente para a esse quadro.

\section{Dimensão Ambiental}

No tocante à presença de mata ciliar, os trechos observados, com níveis mais críticos, foram os trechos 03 e 04 os quais correspondem à área urbana com maior densidade. Encontram-se também, nesses trechos, os locais de intervenção feita nas margens pelo poder público que adotou o viés urbanístico com impermeabilização das mesmas.

Já os trechos 02 e 05 foram classificados como de nível médio, haja vista a supressão de mata ciliar, seja pelos usos agropecuários, seja pela expansão urbana que, mesmo não havendo alta densidade, gera pressão sobre os recursos naturais. Os demais trechos 01 e 06, por estarem afastados dos
Quanto à integridade morfológica, foram identificadas margens instáveis quanto à erosão. Os trechos mais críticos se referem à margem esquerda do trecho 02 e à margem direita do trecho 04. As Figuras 12 e 13 exemplificam as condições encontradas.

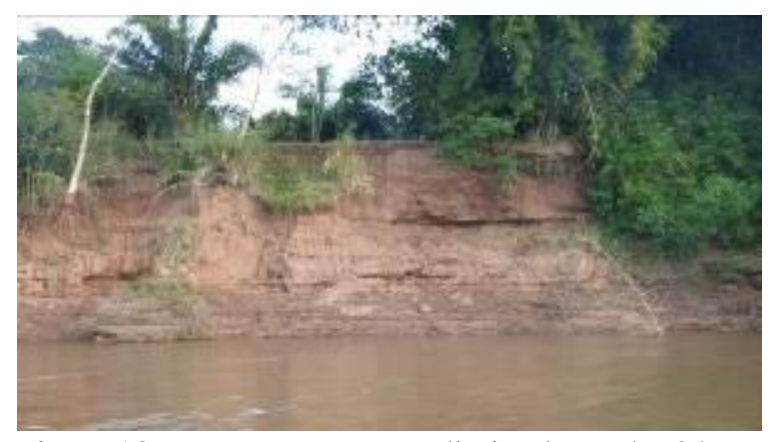

Figura 13. Erosão na margem direita do trecho 04 - Rio Araguaia.

Fonte: Foto da autora (2015).

núcleos urbanos, encontram-se mais preservados, com predominância de vegetação arbórea mais densa.

No que concerne ao indicador qualidade da água, os trechos à montante da confluência dos rios - trechos 01,02 e 03 não possuíam dados quantitativos e a análise se pautou em abordagem qualitativa a partir do que foi visto in loco. Foram demarcados os pontos de efluentes lançados e de presença de materiais sólidos. Tais pontos foram encontrados somente no trecho 03.

Após a confluência dos rios, há uma estação fluviométrica de monitoramento do rio Araguaia, porém, no tocante à qualidade da água, não há dados de coliformes fecais, importante parâmetro de contaminação do rio. $\mathrm{O}$ único dado relevante encontrado foi referente ao oxigênio dissolvido, o qual respaldou a classificação satisfatória de todos os trechos à jusante da estação, trechos 04,05 e 06. Foram analisados os resultados de 2002 a 2015, divulgados pela Agência Nacional de Águas (ANA).

Ressalta-se que o oxigênio dissolvido é um dos parâmetros mais importantes na avaliação da qualidade da água, uma vez que apresenta papel determinante na capacidade de um recurso hídrico em manter e preservar a vida aquática. (SEMA, 2014). 


\section{Dimensão uso e ocupação do solo}

Para o indicador da ocupação da margens, as áreas foram mapeadas sobre imagem satélite. Os trechos que apresentaram maiores porcentagens de ocupação foram: 03 e 04, sendo classificados com nível médio (trecho 03 e a margem direita do trecho 04) e nível alto (margem esquerda do trecho 04).

Contudo, mesmo não havendo um alto nível de porcentagem de ocupação, na maioria dos trechos, os usos referentes a essas ocupações merecem atenção, pois, especificamente, na margem esquerda do trecho 04, pertencente ao município de Barra do Garças, foram encontrados diversos usos (edificações) que impactam negativamente os recursos naturais do local.

Uma dessas edificações é de uso industrial - um frigorífico, que além de ser uma atividade impactante, também está ocupando a APP de forma irregular, visto que distancia somente $40 \mathrm{~m}$ do leito do rio Araguaia.

Ainda nesse trecho, encontra-se o Parque Salomé José Rodrigues (Porto do Baé), que se trata de espaço multiuso, composto de arquibancada com arena para eventos e apresentações, quadra poliesportiva, quiosques, lanchonetes, restaurante flutuante, rampas de acesso para embarcações, uma arquibancada de concreto para eventos náuticos e lanchonetes. A intervenção das margens segue o viés urbanístico, com presença de artificialização das mesmas.

Ressalta-se que, devido ao fluxo intenso de pessoas no local, é bem provável que resíduos sólidos sejam descartados no rio, seja pelo escoamento pluvial ou ainda pelo vento. Além disso, o embarque e desembarque de embarcações pode contribuir, de alguma forma, para os processos erosivos.

Já em relação à margem direita do trecho 04, têm-se a área beira-rio de Aragarças, onde foi construída uma avenida com calçadão e acesso à praia Quarto Crescente. Essa é a praia mais movimentada na temporada e corresponde a $51,88 \%$ do uso da margem. Com essa finalidade turística, a classificação do uso foi especificada como média.

Finalizando, os usos dos trechos 02 e 06 são residenciais, como pequenas chácaras e sítios. As Figuras 14 e 15 apontam as porcentagens de uso para cada trecho.

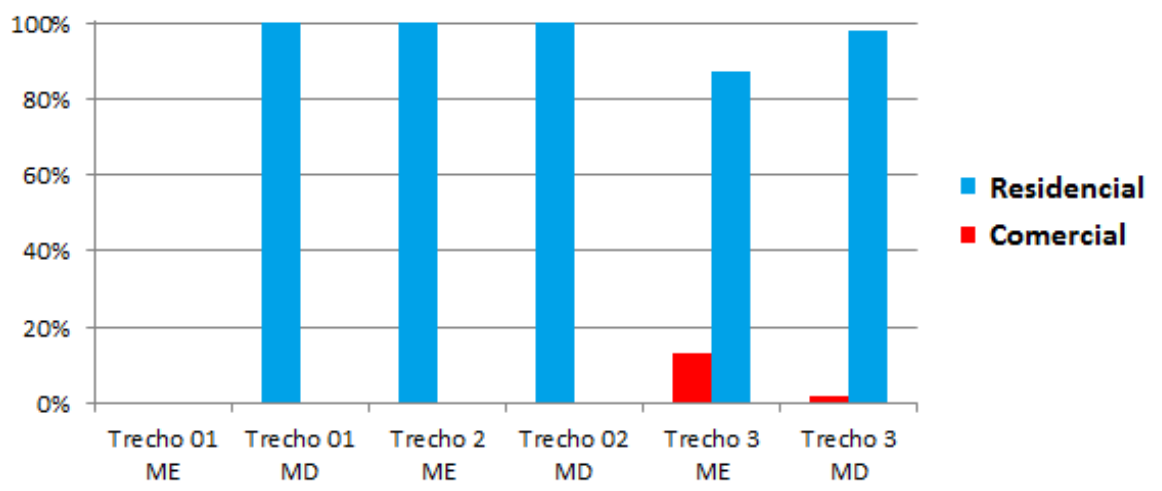

Figura 14. Porcentagem dos tipos de usos nos Trechos 01,02 e 03 do rio Araguaia. 


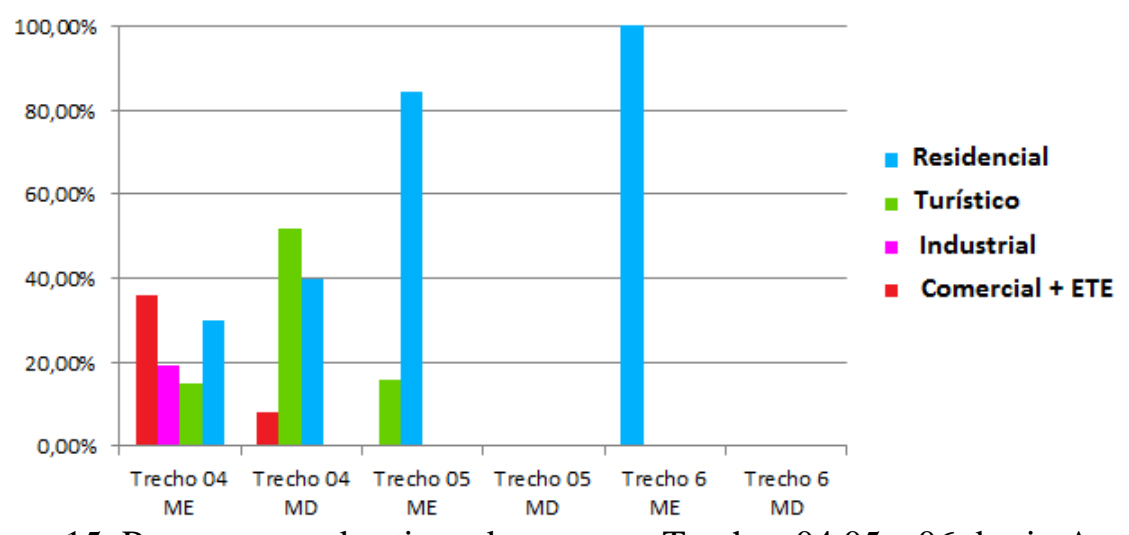

Figura 15. Porcentagem dos tipos de usos nos Trechos 04,05 e 06 do rio Araguaia

Portanto, nota-se a predominância do uso residencial e turístico, exceto pela margem esquerda do trecho 04, onde há usos comerciais e industrial os quais geram impactos significativos para a margem do rio.

\section{Resultado Geral}

Os trechos analisados estão inseridos em sub-bacias com média e alta impermeabilização nas áreas correspondentes aos núcleos urbanos que consequentemente são mais adensados (trechos 03 e 04). Na parte mais periférica, as sub-bacias possuem baixa impermeabilização e correspondem aos demais trechos.

Os tempos de concentração são pequenos, o que influencia em rápida contribuição do escoamento superficial e nos eventos de inundação. Já em relação à vulnerabilidade socioambiental, o trecho $03 \mathrm{e}$ a margem direita do trecho 04, em Aragarças, possuem manchas de nível médio, que cobrem a maioria dos trechos.

Seguem, nos Quadro 6 e 7, os resultados do trecho 03 e 04 do rio Araguaia, os quais apresentaram uma maior alteração em relação à condição natural.

Quadro 6. Resultado dos indicadores para o Trecho 03 do rio Araguaia.

\begin{tabular}{|c|c|c|c|c|c|c|c|c|}
\hline TRECHO 03 & & Margem Esque & & & Marger & Direi & & \\
\hline Dimensão & Indicadores & Alteração em relação à co & ção natural & Alteração $€$ & relaça & o à cor & ção n & ural \\
\hline Fluvial & & $\begin{array}{lll} & \text { Muito } \\
\text { Baixa }\end{array}$ & $\begin{array}{l}\text { Alta } \quad \begin{array}{l}\text { Muitc } \\
\text { Alta }\end{array} \\
\end{array}$ & $\begin{array}{l}\text { Muito } \\
\text { Baixa }\end{array}$ & Baixa & Média & Alta & $\begin{array}{l}\text { Muito } \\
\text { Alta }\end{array}$ \\
\hline & Des. Longitudinal & & & & & & & \\
\hline & Seção transversal & & & 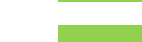 & & & & \\
\hline & Integ. morfológica & & & & & & & \\
\hline & Resultado parcial & & & & & & & \\
\hline Ambiental & Qualidade da água & & & & & & & \\
\hline & Presença de mata ciliar & & & & & & & \\
\hline & Resultado parcial & & & & & & & \\
\hline Uso e & Ocupação das margens & & & & & & & \\
\hline ocupação & Uso das margens & & & & & & & \\
\hline & Resultado parcial & & & & & & & \\
\hline Bacia e & Impermeabilização & & & & & & & \\
\hline sub-bacias & Tempo de conc. & & & & & & & \\
\hline & Vuln. socioambiental & & & & & & & \\
\hline & Resultado parcial & & & & & & & \\
\hline & Aspecto geral & & & & & & & \\
\hline
\end{tabular}

Rio Araguaia depois da confluência com o Rio das Garças 
Quadro 7. Resultado dos indicadores para o Trecho 04 do rio Araguaia

\begin{tabular}{|c|c|c|c|c|c|c|c|c|c|c|c|}
\hline \multirow{3}{*}{$\begin{array}{l}\text { TRECHO } 04 \\
\text { Dimensão } \\
\text { Fluvial }\end{array}$} & \multirow{2}{*}{ Indicadores } & \multicolumn{5}{|c|}{ Margem Esquerda } & \multicolumn{5}{|c|}{ Margem Direita } \\
\hline & & \multicolumn{5}{|c|}{ Alteração em relação à condição natural } & \multicolumn{5}{|c|}{ Alteração em relação à condição natural } \\
\hline & & $\begin{array}{r}\text { Muito } \\
\text { Baixa }\end{array}$ & Baixa & Média & Alta & $\begin{array}{l}\text { Muito } \\
\text { Alta }\end{array}$ & $\begin{array}{c}\text { Muito } \\
\text { Baixa }\end{array}$ & Baixa & Média & Alta & $\begin{array}{l}\text { Muito } \\
\text { Alta }\end{array}$ \\
\hline \multicolumn{12}{|c|}{ Des. Longitudinal } \\
\hline & \multicolumn{11}{|l|}{ Seção transversal } \\
\hline & \multicolumn{11}{|l|}{ Integ. morfológica } \\
\hline & \multicolumn{11}{|l|}{ Resultado parcial } \\
\hline \multirow[t]{3}{*}{ Ambiental } & \multicolumn{11}{|l|}{ Qualidade da água } \\
\hline & \multicolumn{11}{|l|}{ Presença de mata ciliar } \\
\hline & \multicolumn{11}{|l|}{ Resultado parcial } \\
\hline \multirow{3}{*}{$\begin{array}{l}\text { Uso e } \\
\text { ocupação }\end{array}$} & Ocupação das margens & & & & & & & & & & \\
\hline & Uso das margens & & & & & & & & & & \\
\hline & Resultado parcial & & & & & & & & & & \\
\hline \multirow{5}{*}{$\begin{array}{l}\text { Bacia e } \\
\text { sub-bacias }\end{array}$} & Impermeabilização & & & & & & & & & & \\
\hline & Tempo de conc. & & & & & & & & & & \\
\hline & Vuln. socioambiental & & & & & & & & & & \\
\hline & Resultado parcial & & & & & & & & & & \\
\hline & Aspecto geral & & & & & & & & & & \\
\hline
\end{tabular}

Dos trechos analisados, os mais impactados se referem à margem esquerda do trecho 03, pertencente ao Pontal do Araguaia, e o trecho 04, em ambas as margens, pertencente a Barra do Garças e Aragarças. Tal resultado é explicado pelo fato desses trechos serem os mais urbanizados com áreas mais extensas de supressão da mata ciliar. Verifica-se que o trecho 04 possui diversos usos impactantes em sua margem.

Também foram verificados pontos de erosão a montante (margem esquerda do trecho 02) e a jusante (margem direita do trecho 04) do ponto de confluência com o rio Araguaia.

\section{Resultado final}

Após encontrar os resultados para cada trecho, foi elaborada a Figura 16. 


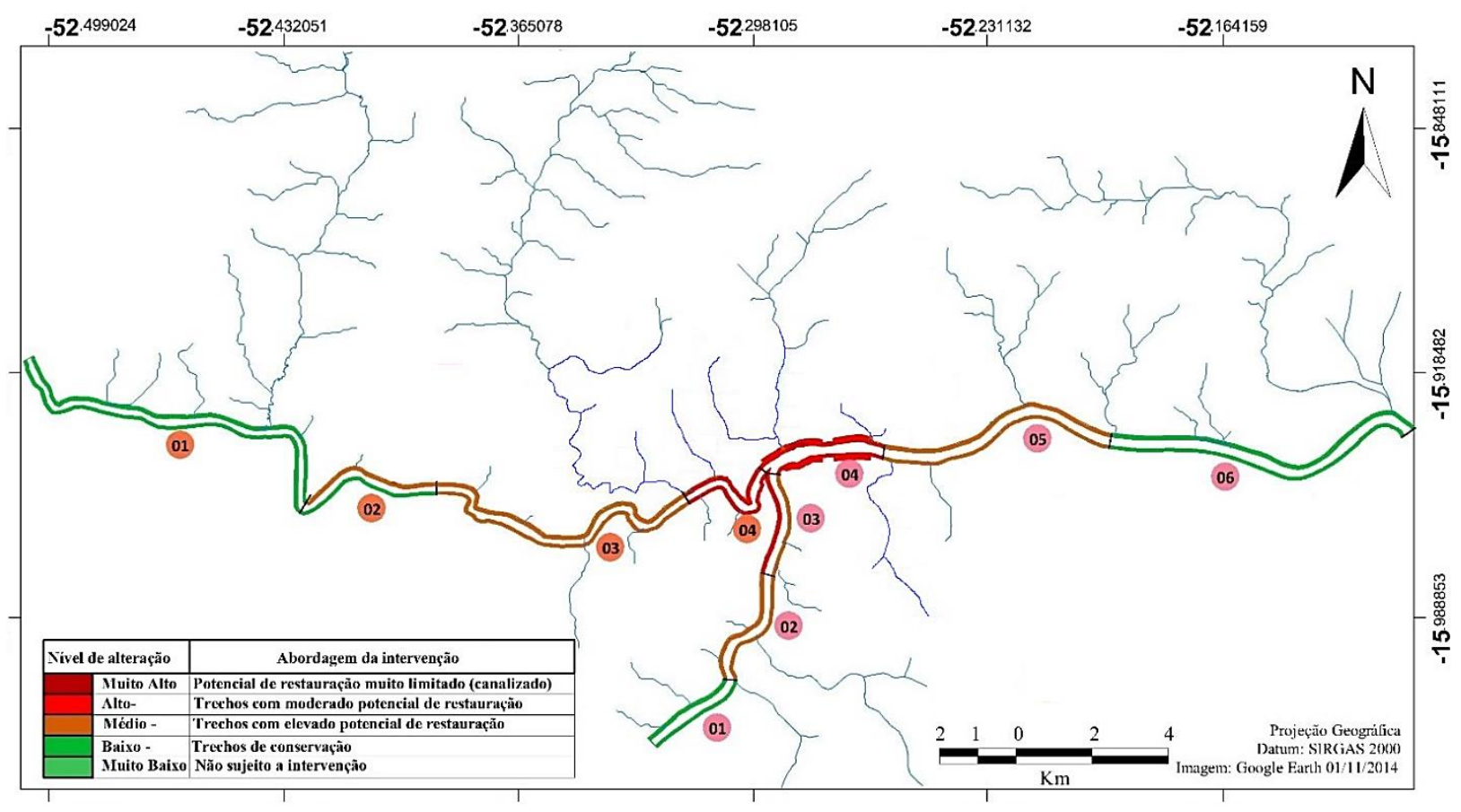

Figura 16. Resultado final da metodologia, trecho a trecho.

Verifica-se que os trechos nas periferias apresentaram níveis baixos de alteração em relação a condição natural, o que requer intervenções preservacionistas, com medidas para a conservação de seus recursos naturais.

Um fator preocupante é o aumento crescente, em extensão e intensidade da instabilidade das margens dos rios Garças e Araguaia. Os trechos 02 e 04 do rio Araguaia e os trechos 03 e 04 do rio das Garças estavam bem afetados.

Portanto, as intervenções nesses trechos devem priorizar técnicas de manutenção dos taludes desprotegidos em decorrência de supressão da mata ciliar. Planos de reflorestamento dessas áreas podem ser feitos, com estudo de viabilidade técnica e econômica do reflorestamento por faixas ou linhas.

Os trechos 04 do rio das Garças e trechos 03 e 04 do rio Araguaia possuem as margens mais ocupadas e, portanto, possuem pontos que necessitam de uma abordagem especial, visando impedir a degradação ambiental pelas propriedades particulares presentes em alguns trechos da APP, bem como localizam-se as "praias" onde se concentram grande atividade antrópica.
Nota-se que a utilização frequente pelo ser humano das áreas que recebem proteção específica, no caso em destaque, a APP, pode ocasionar degradações que eventualmente poderão se transformar em impacto e dano ambiental.

Em razão disso é importante que sejam implantados instrumentos para a preservação dessas áreas, como um programa de educação ambiental, controle do turismo local e manejo dos resíduos sólidos produzidos.

\section{Conclusão}

A metodologia proposta para o diagnóstico de cursos de água em áreas urbanas procurou incluir aspectos ambientais e urbanos voltados ao diagnóstico da relação rio-cidade, e foi estruturada em três etapas, as quais foram bem demonstradas ao longo do trabalho mediante sua aplicação na área urbana de três cidades: Barra do Garças- MT, Pontal do Araguaia - MT e Aragarças- GO, no Brasil.

Nesse estudo de caso diversas questões foram analisadas, a saber: a) o uso e ocupação do solo das sub-bacias, que exercem pressão sobre as margens; $b$ ) a influência do 
escoamento superficial nas dinâmicas de cheias; c) a vulnerabilidade socioambiental advindas das ocupações em áreas de risco.

Após sobrepor esses elementos, foram preenchidas as lacunas encontradas mediante a adaptação de modelos desenvolvidos por outros autores, adequando-os à complexa realidade urbana, o que possibilitou identificar a relação natureza e sociedade no contexto urbano.

Dessa forma a aplicação da metodologia foi capaz de apontar um resultado eficaz, indicando na área de estudo, que a degradação ambiental dos corpos hídricos e o aumento de áreas de vulnerabilidade socioambiental, decorrentes de riscos de inundações, foi potencializada pela falta de uma interface entre os aspectos urbanos e ambientais no trato das margens dos rios urbanos bem como de suas sub-bacias.

Sendo assim, conclui-se que tal diagnóstico, demonstrando o nível de alteração em relação à condição natural de cada trecho do curso fluvial por meio de um conjunto de indicadores, poderá direcionar políticas públicas, notadamente propostas de conservação ou intervenção a serem implementadas às margens dos corpos hídricos para casos semelhantes.

\section{Agradecimentos}

À Coordenação de Aperfeiçoamento de Pessoal de Nível Superior - Capes - pelas bolsas de estudo.

\section{Referências}

Cardoso, A. S.; Baptista, M. B., 2009. Avaliação e classificação de cursos de água em bacias urbanas. In: Simpósio brasileiro de recursos hídricos, 8., Campo Grande. Anais... Porto Alegre: ABRH.

Cardoso, A. S., 2012. Proposta de metodologia para orientação de processos decisórios relativos a intervenções em cursos de água em áreas urbana. Tese (Doutorado). Belo Horizonte, Universidade Federal de Minas Gerais.

(CWP) Center for Watershed Protection, 2005. Urban Subwatershed Restoration Manual Series. An Integrated Framework to Restore Small Urban Watersheds.

MATO GROSSO, Secretaria de Estado do Meio Ambiente - SEMA, 2014. Relatório de monitoramento da qualidade da água da região hidrográfica Tocantins-Araguaia 2010 e 2011. Araújo, A. A., Figueiredo, S. B. (orgs.). Cuiabá: SEMA/MT.

Mello, S. S., 2008. As funções ambientais e as funções de urbanidade em margens de cursos d'água. Oculum Ensaios Revista de Arquitetura e Urbanismo, Campinas, 496.

Rezende, G. B. M, 2015. As cidades e as águas: uma abordagem metodológica das vulnerabilidades socioambientais dos rios Araguaia e das Garças, nos municípios de Barra do Garças, Pontal do Araguaia e Aragarças. Tese (Doutorado em Recursos Naturais). Campina Grande, Universidade Federal de Campina Grande.

Rezende, G. B. M., Araújo, S. M. S, 2015. Análise da taxa de impermeabilização e tempo de concentração nas sub-bacias da área urbana de Barra do Garças - MT, Pontal do Araguaia - MT e Aragarças GO. Revista Verde de Agroecologia e Desenvolvimento Sustentável [online] 10.Disponível:

http://dx.doi.org/10.18378/rvads.v10i5.37 27. Acesso: 19 nov. 2017. 